\title{
The vapor pressures and activities of dicarboxylic acids reconsidered: the impact of the physical state of the aerosol
}

\author{
V. Soonsin ${ }^{1}$, A. A. Zardini ${ }^{2}$, C. Marcolli ${ }^{1}$, A. Zuend ${ }^{3}$, and U. K. Krieger ${ }^{1}$ \\ ${ }^{1}$ Institute for Atmospheric and Climate Science, ETH Zurich, Zurich, Switzerland \\ ${ }^{2}$ Department of Chemistry, University of Copenhagen, Copenhagen, Denmark \\ ${ }^{3}$ Department of Chemical Engineering, California Institute of Technology, Pasadena, California, USA
}

Received: 23 July 2010 - Published in Atmos. Chem. Phys. Discuss.: 27 August 2010

Revised: 2 December 2010 - Accepted: 3 December 2010 - Published: 10 December 2010

\begin{abstract}
We present vapor pressure data of the $\mathrm{C}_{2}$ to $\mathrm{C}_{5}$ dicarboxylic acids deduced from measured evaporation rates of single levitated particles as both, aqueous droplets and solid crystals. The data of aqueous solution particles over a wide concentration range allow us to directly calculate activities of the dicarboxylic acids and comparison of these activities with parameterizations reported in the literature. The data of the pure liquid state acids, i.e. the dicarboxylic acids in their supercooled melt state, exhibit no even-odd alternation in vapor pressure, while the acids in the solid form do. This observation is consistent with the known solubilities of the acids and our measured vapor pressures of the supercooled melt. Thus, the gas/particle partitioning of the different dicarboxylic acids in the atmosphere depends strongly on the physical state of the aerosol phase, the difference being largest for the even acids.

Our results show also that, in general, measurements of vapor pressures of solid dicarboxylic acids may be compromised by the presence of polymorphic forms, crystalline structures with a high defect number, and/or solvent inclusions in the solid material, yielding a higher vapor pressure than the one of the thermodynamically stable crystalline form at the same temperature.
\end{abstract}

\section{Introduction}

There is a considerable interest in understanding the gas/particle partitioning of organic compounds, owing to the high abundance of organic species in the atmospheric aerosol (Zhang et al., 2007). In particular, for semivolatile sub-

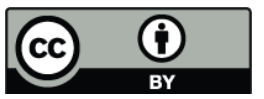

Correspondence to: V. Soonsin (vacharaporn.soonsin@env.ethz.ch) stances the partitioning strongly influences the particulate matter burden in the troposphere, the radiative properties of the aerosol, the cloud processing and the heterogeneous chemistry (IPCC, 2007). While the organic fraction in atmospheric aerosol particles is likely to consist of a large number of compounds (Goldstein and Galbally, 2007), it is crucial to know the vapor pressure of the pure compounds under ambient conditions to predict the partitioning (e.g., Pankow, 1994; Clegg et al., 2008; Hallquist et al., 2009; Barley and McFiggans, 2010; Zuend et al., 2010). Among the oxygenated organic species short chain dicarboxylic acids are known to be ubiquitous (e.g., Decesari et al., 2006; Legrand et al., 2007) with average concentrations ranging from a few $\mathrm{ng} \mathrm{m}^{-3}$ in remote marine aerosols (Wang et al., 2006) to $2 \mu \mathrm{g} \mathrm{m}^{-3}$ in biomass burning aerosols (Kundu et al., 2010). Although the vapor pressures of the dicarboxylic acids have been studied intensely, the room temperature pressures of different studies disagree, with differences up to two orders of magnitude for some compounds. Equally important for a better understanding of gas/particle partitioning are thermodynamic models which allow estimating the activity of organic species in complex aqueous solutions (e.g., Clegg and Seinfeld, 2006a,b; Chang and Pankow, 2006, 2010; Zuend et al., $2008,2010)$. Activity data of binary, ternary, and multicomponent aqueous solutions over a wide range of concentrations from dilute to supersaturated solutions are needed to further the development of these models. Vapor pressure measurements over binary aqueous solutions allow the organic activity to be directly obtained and hence serve as constraints for these models.

Several techniques have been used to obtain vapor pressure data of dicarboxylic acids: Knudsen's effusion methods using different detection techniques, namely, gas phase concentration by condensation and subsequent titration (Noyes and Wobbe, 1926), torsion-effusion (de Kruif et al.,

Published by Copernicus Publications on behalf of the European Geosciences Union. 
Table 1. Selected physical properties of the dicarboxylic acids used in this study.

\begin{tabular}{|c|c|c|c|c|c|c|c|}
\hline Name & \# C & $\begin{array}{c}M \\
\left(10^{-3} \mathrm{~kg} \mathrm{~mol}^{-1}\right)\end{array}$ & $\begin{array}{l}\text { Density }{ }^{\mathrm{a}} \\
\left(10^{3} \mathrm{~kg} \mathrm{~m}^{-3}\right)\end{array}$ & $\begin{array}{l}\text { Solubility } \\
\left(\mathrm{mol} \mathrm{kg}^{-1}\right)\end{array}$ & $\begin{array}{c}\text { Melting } \\
\text { point }^{\mathrm{a}}\left({ }^{\circ} \mathrm{C}\right)\end{array}$ & $\begin{array}{l}\text { ERH } \\
(\%)\end{array}$ & $\begin{array}{l}\text { Purity } \\
(\%)\end{array}$ \\
\hline oxalic & 2 & 90.04 & 1.905 & 1.25 & 189.5 & $\begin{array}{c}77.3^{\mathrm{c}} \\
51.8-56.7^{\mathrm{d}}\end{array}$ & $\begin{array}{c}\geq 99.5 \\
\text { (dihydrate) }\end{array}$ \\
\hline malonic & 3 & 104.06 & 1.616 & 15.22 & 135.6 & no $^{\mathrm{c}, \mathrm{d}}$ & $\geq 99$ \\
\hline succinic & 4 & 118.09 & 1.566 & 0.66 & 188 & $\begin{array}{l}51-53^{\mathrm{c}} \\
55-59^{\mathrm{d}}\end{array}$ & $\geq 99.5$ \\
\hline glutaric & 5 & 132.12 & 1.414 & 10.80 & 99 & $\begin{array}{l}<5-43^{\mathrm{c}} \\
29-33^{\mathrm{d}}\end{array}$ & $\sim 99$ \\
\hline
\end{tabular}

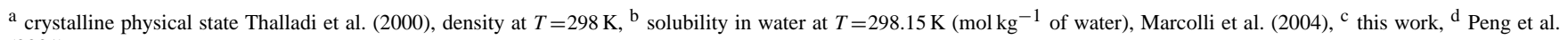
(2001).

1975; de Wit et al., 1983), mass-loss detection (Bradley and Cotson, 1953; de Wit et al., 1983; Ribeiro da Silva et al., 1999, 2001) or gas phase mass spectrometry detection (Booth et al., 2009, 2010); temperature programmed desorption (TPD) with mass spectrometry detection (Chattopadhyay and Ziemann, 2005; Cappa et al., 2007, 2008); measurements of evaporation rates of aerosol particles using either tandem differential mobility analyzers (TDMA) (Tao and McMurry, 1989; Bilde and Pandis, 2001; Bilde et al., 2003; Riipinen et al., 2006; Koponen et al., 2007; Salo et al., 2010) or sizing evaporating single aerosol particles in an electrodynamic balance (EDB) (Zardini et al., 2006, 2009, 2010; Pope et al., 2010). The observation of an even-odd alternation in vapor pressures of the $\mathrm{C}_{3}$ to $\mathrm{C}_{9}$ dicarboxylic acids by Bilde et al. (2003) and subsequent measurements by other authors stimulated a discussion on the influence of the physical state of the aerosol on vapor pressure.

TDMA and EDB techniques are the only techniques which allow the vapor pressure of semivolatile substances in an aqueous solution to be directly determined, namely, by measuring the size change with time of an evaporating aqueous aerosol at a constant temperature and relative humidity, i.e. at a fixed and known concentration of the binary aerosol. The EDB technique is unique in the sense that it allows the unambiguous identification of the physical state of the particle during evaporation. This way the vapor pressure of a solid particle can be directly compared with the corresponding one of a saturated solution.

We used the EDB technique to study the $\mathrm{C}_{2}$ to $\mathrm{C}_{5}$ dicarboxylic acids shown in Table 1 in the solid and liquid state. In the following we briefly introduce the experimental setup, present our data, their analysis and provide an interpretation of vapor pressures and activities of the acids in aqueous solution as well as of the vapor pressures of the solid dicarboxylic acid particles.

\section{Experimental}

The basic experimental setup (Colberg et al., 2004) and the method of obtaining vapor pressures from measured evaporation rates has been described previously (Zardini et al., 2006, 2009, 2010). Briefly, a single liquid, aqueous aerosol particle is inductively charged and injected into the EDB using an ink jet single particle generator filled with a diluted aqueous solution and then levitated by the electric field in the EDB. The DC-field used to balance gravitation allows to deduce mass changes and in a binary system the composition change of the particle. Temperature, relative humidity (RH) and total pressure (buffer gas is nitrogen) are adjusted and the evaporation of the particle is monitored by precision sizing, using optical resonance spectroscopy (Zardini et al., 2006). By keeping temperature and relative humidity fixed, the composition and temperature of a slowly evaporating binary aqueous aerosol particle is kept constant as well. Solid particles are either injected directly into the EDB by contact charging or aqueous solution particles are transformed to solids by efflorescence through drying. Millipore water (Resistivity $\geq 18.2 \mathrm{M} \Omega \mathrm{cm}$ ) and dicarboxylic acids (Table 1) were purchased from Sigma-Aldrich with purities of $99 \%$ or higher and used without any further purification for the preparation of the solutions fed into the particle generator. To distinguish unambiguously liquid (spherical) particles from solid (non-spherical) particles the 2-dimensional angular scattering (TAOS) pattern is monitored continuously using a CCD camera (Braun and Krieger, 2001).

The raw data of our experiments consist of evaporation rates, $\frac{d r^{2}}{d t}$ (where $r$ is the particle radius), for various particles measured at fixed temperatures, total buffer gas pressures and - (if aqueous solution droplets) - fixed relative humidities, see Table 2 for an example of raw data. We measured evaporation rates at least for five different particles, injected from separately prepared aqueous solutions of the respective dicarboxylic acids at several relative humidities and at least two different temperatures. Measurements are performed at 
Table 2. Raw data of the glutaric acid experiments: temperature, $\mathrm{RH}$, glutaric acid mole fraction, $x$, as calculated from measured RH using UNIFAC-Peng, glutaric acid gas phase diffusion coefficient, $D$, solution density, $\rho$, and evaporation rate, needed to calculate the vapor pressure of the acid, $p^{\mathrm{L}}$, see Eq. (1). The pressure of the buffer gas $\left(\mathrm{N}_{2}\right)$ was kept constant at $800 \mathrm{hPa}$ in all measurements.

\begin{tabular}{rrrcccc}
\hline$T(\mathrm{~K})$ & $\mathrm{RH}(\%)$ & $x$ & $D\left(10^{-6} \mathrm{~m}^{2} \mathrm{~s}^{-1}\right)$ & $\rho\left(\mathrm{g} \mathrm{cm}^{-3}\right)$ & $\frac{d r^{2}}{d t}\left(\mathrm{~nm}^{2} \mathrm{~s}^{-1}\right)$ & $p^{\mathrm{L}}\left(10^{-5} \mathrm{~Pa}\right)$ \\
\hline 281.3 & 4.5 & 0.934 & 7.04 & 1.336 & 39.5 & $6.6 \pm 2.1$ \\
281.3 & 10.6 & 0.845 & 7.04 & 1.328 & 39.1 & $6.4 \pm 2.0$ \\
281.3 & 16.7 & 0.775 & 7.04 & 1.322 & 37.9 & $6.1 \pm 1.9$ \\
281.3 & 21.9 & 0.720 & 7.04 & 1.316 & 35.9 & $5.6 \pm 1.8$ \\
281.3 & 27.3 & 0.660 & 7.04 & 1.310 & 34.7 & $5.3 \pm 1.7$ \\
281.3 & 32.7 & 0.616 & 7.04 & 1.304 & 32.4 & $4.9 \pm 1.6$ \\
281.3 & 37.7 & 0.574 & 7.04 & 1.298 & 29.9 & $4.4 \pm 1.5$ \\
281.3 & 44.5 & 0.517 & 7.04 & 1.289 & 24.8 & $3.6 \pm 1.1$ \\
281.3 & 54.6 & 0.435 & 7.04 & 1.274 & 22.7 & $3.1 \pm 1.1$ \\
281.3 & 70.7 & 0.313 & 7.04 & 1.242 & 12.7 & $1.5 \pm 0.6$ \\
290.9 & 1.0 & 0.984 & 7.52 & 1.324 & 241 & $38 \pm 12$ \\
290.9 & 5.0 & 0.925 & 7.52 & 1.320 & 226 & $36 \pm 11$ \\
290.9 & 33.7 & 0.606 & 7.52 & 1.290 & 153 & $22 \pm 6.7$ \\
290.9 & 44.0 & 0.517 & 7.52 & 1.278 & 100 & $14 \pm 4.3$ \\
290.9 & 49.4 & 0.477 & 7.52 & 1.271 & 108 & $15 \pm 4.5$ \\
290.9 & 51.2 & 0.462 & 7.52 & 1.268 & 126 & $17 \pm 5.2$ \\
290.9 & 60.0 & 0.395 & 7.52 & 1.254 & 90.8 & $11 \pm 3.6$ \\
290.9 & 66.5 & 0.345 & 7.52 & 1.242 & 88.1 & $11 \pm 3.3$ \\
290.9 & 75.0 & 0.257 & 7.52 & 1.213 & 82.5 & $8.7 \pm 2.7$ \\
290.9 & 84.5 & 0.195 & 7.52 & 1.186 & 65.1 & $6.0 \pm 1.9$ \\
290.9 & 90.0 & 0.135 & 7.52 & 1.151 & 48.0 & $3.6 \pm 1.2$ \\
290.9 & 94.5 & 0.061 & 7.52 & 1.086 & 39.7 & $1.7 \pm 0.6$ \\
303.2 & 5.0 & 0.925 & 8.16 & 1.301 & 941 & $142 \pm 43$ \\
\hline
\end{tabular}

constant relative humidity, which means constant aqueous solution concentration within the droplet during evaporation. Therefore the evaporation of the acid is accompanied by a proportional (in terms of molecules) evaporation of water to the gas phase. To calculate vapor pressures of the acids in the liquid state, $p_{\mathrm{acid}}^{\mathrm{L}}$, from evaporation rates, $\frac{d r^{2}}{d t}$, in the continuum regime of diffusion, we need to know the composition of the particle, expressed as mole fraction of the dicarboxylic acid, $x$, the density of the particle, $\rho$, the molar mass of the acid, $M_{\text {acid }}$, the molar mass of water, $M_{\mathrm{H}_{2} \mathrm{O}}$ and the diffusivity, $D$, of the dicarboxylic acid in the buffer atmosphere:

$p_{\mathrm{acid}}^{\mathrm{L}}=-\frac{1}{2} \frac{d r^{2}}{d t} \frac{x \rho R T}{\left(x M_{\mathrm{acid}}+(1-x) M_{\mathrm{H}_{2} \mathrm{O}}\right) D}$

For solid, in general non-spherical particles, we need to consider the actual particle shape. The only information we gain from the TAOS pattern is the non-sphericity of the solid particle but not its actual shape. Using an equivalent sphere radius approximation we can still deduce evaporation rates from optical resonance spectroscopy by assigning a size parameter to a specific resonance in the spectra and following its temporal evolution. This is explained in detail in Zardini et al. (2009, 2010). The results depend only slightly on whether the equivalent sphere radius is assigned to the minimum enclosing ball radius of the non-spherical particle or its mean radius. We estimated the relative error in vapor pressure using this approximation to evaluate the optical resonance spectra together with uncertainties in gas phase diffusivities to be $35 \%$. Alternatively, we may use the mass change data obtained from the DC voltage compensating the gravitational force to deduce evaporation rates. However, for low vapor pressures with corresponding small evaporation rates, the precision in the mass change rates is limited by the overall drift of the DC balancing voltage feedback loop, which relies on a video image of the particle. This becomes especially important for small particles. It turned out that only for high vapor pressures (corresponding to temperatures above $300 \mathrm{~K}$ ) the pressures inferred from mass change data are of the same precision as those inferred from the optical resonance spectra of the solid particles.

While our setup allows the measurement of concentration changes with relative humidity, for convenience we use the UNIFAC parameterization by Peng et al. (2001) (UNIFACPeng) to calculate the binary aqueous solution concentration in equilibrium with the measured relative humidity, assuming an undissociated dicarboxylic acid. This is justified because the UNIFAC-Peng yields a good agreement between measured and calculated water uptake of dicarboxylic acids. However, we also checked the consistency of the water activities calculated using UNIFAC-Peng with our measurements 
of concentration changes at various relative humidities and found agreement within experimental error. We calculated the gas phase diffusivities as described in Bird et al. (2007), using the Lennard-Jones parameters as given in Bilde et al. (2003).

\section{Data analysis and results}

Our data evaluation requires an iterative procedure to determine enthalpies of vaporization, activities of the solutes (dicarboxylic acids) and the vapor pressures of supercooled melts and saturated solutions. We use glutaric acid as an example to illustrate this analysis in some detail and present the data of the shorter chain dicarboxylic acids in the following.

\subsection{Glutaric acid}

We measured the evaporation rates of 5 different aqueous glutaric acid particles at three different temperatures (281.3 K, $290.9 \mathrm{~K}$ and $303.2 \mathrm{~K}$ ) and various relative humidities as given in Table 2. Aqueous glutaric acid droplets exhibit a strong variability in efflorescence relative humidity (ERH) (Zardini et al., 2008). With some droplets we were able to supersaturate the aqueous solution down to a RH of about $1 \%$ without the occurrence of crystallization. While the reason for the variability in ERH remains unclear, it allows measurements over a wide range of concentrations.

For each measurement we adjusted temperature and relative humidity and measured the evaporation rate over a time span of at least $10000 \mathrm{~s}$ and up to $100000 \mathrm{~s}$ depending on the magnitude of the rate. We used the measured RH to calculate the equilibrium concentration of the aqueous droplet using UNIFAC-Peng (298.15 K) neglecting any temperature dependence of water activity. To calculate vapor pressures from the measured radius changes, knowledge of the density of the particle as well as the diffusivity of glutaric acid in the gas phase is required (Zardini et al., 2006). Densities as given in Table 2 were calculated assuming ideal mixing and taking the molar volume of glutaric acid from the measurements of Ben-Hamo et al. (2007) at the highest concentration $\left(5.94\right.$ molar, $V_{\text {Glutaric }}(281.3 \mathrm{~K})=98.7 \mathrm{~cm}^{3} \mathrm{~mol}^{-1}$, $V_{\text {Glutaric }}(290.9 \mathrm{~K})=99.7 \mathrm{~cm}^{3} \mathrm{~mol}^{-1}, \quad V_{\text {Glutaric }}(302.2 \mathrm{~K})=$ $101.2 \mathrm{~cm}^{3} \mathrm{~mol}^{-1}$ ) interpolated to the respective temperature. It is difficult to calculate the cumulative error in vapor pressure, because we can only estimate the error in concentration, diffusivity and density, while the error in rate measurement is $5 \% \pm 0.5 \mathrm{~nm}^{2} \mathrm{~s}^{-1}$. Overall, we estimate a relative error in vapor pressure, $p^{\mathrm{L}}$, to be $30 \%$ plus an absolute error of $\pm 1.25 \times 10^{-6} \mathrm{~Pa}$, as given in the last column of Table 2 .

Figure 1 shows that liquid state vapor pressures of glutaric acid deviate increasingly from Raoult's law as the aqueous solution becomes more dilute with respect to glutaric acid. To determine the vapor pressure of the supercooled melt $(x=1)$, we perform a linear regression

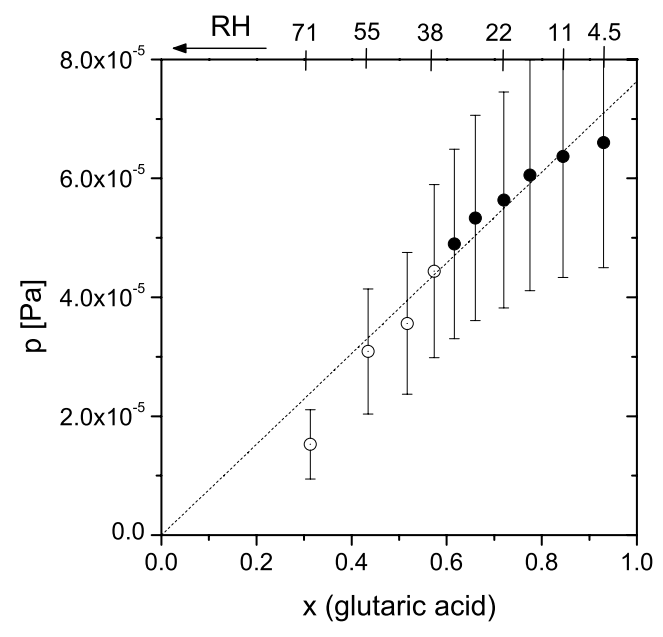

Fig. 1. Vapor pressure from evaporation rates of aqueous glutaric acid droplets at $281.3 \mathrm{~K}$ as a function of glutaric acid mole fraction. Data at concentrations larger than $x=0.6$ are shown as solid $\bullet$, see text. Dotted line shows a fit to the solid circles, to determine the vapor pressure of the pure, supercooled liquid state.

for the data points with concentrations larger than $x=$ 0.6 (solid circles in Fig. 1) neglecting non-ideality at these concentrations close to the pure solute. As illustrated in Fig. 1, we obtain a pure compound (indicated by superscript $\circ$ ) vapor pressure, $p^{\circ, \mathrm{L}}$, at $T=281.3 \mathrm{~K}$ for the supercooled melt (indicated as liquid state L) of glutaric acid of $p^{\circ, \mathrm{L}}(281.3 \mathrm{~K})=(7.6 \pm 2.3) \times 10^{-5} \mathrm{~Pa}$. Similarly we determine $p^{\circ, \mathrm{L}}(290.9 \mathrm{~K})=(3.9 \pm 1.2) \times 10^{-4} \mathrm{~Pa}$ and $p^{\circ, \mathrm{L}}(303.2 \mathrm{~K})=(1.5 \pm 0.4) \times 10^{-3} \mathrm{~Pa}$. By applying the Clausius-Clapeyron equation,

$\frac{d \ln p^{\circ, \mathrm{L}}}{d\left(\frac{1}{T}\right)}=-\frac{\Delta H_{\text {vap }}^{\ominus}}{R}$

and assuming that the enthalpy change of vaporization, $\Delta H_{\text {vap }}^{\ominus}$, is constant over the temperature range of our measurements, we obtain $\Delta H_{\text {vap }}^{\ominus}=97 \pm 8 \mathrm{~kJ} \mathrm{~mol}^{-1}$ and the vapor pressure of the supercooled melt at $T=298.15 \mathrm{~K}$, $p^{\circ, \mathrm{L}}=(8.6 \pm 2.6) \times 10^{-4} \mathrm{~Pa}$. This allows us to directly calculate the activity of glutaric acid, $a^{(x)}$, for all measured concentrations at this temperature using $a^{(x)}=p^{\mathrm{L}} / p^{\circ, \mathrm{L}}$, see Fig. 2.

Our data agree best with the UNIFAC parameterization of Peng et al. (2001) and the (corrected, see Appendix A) parameterization of Clegg and Seinfeld (2006a) who deduced their parameterization from water activity data at room temperature only. The parameterization of Ming and Russell (2002) is in disagreement with our data, this parameterization deviates oppositely from Raoult's law to what we observe, as does the UNIFAC Dortmund parameterization (taken from (Koponen et al., 2007)) as well as the van Laar parameterization of Koponen et al. (2007). 


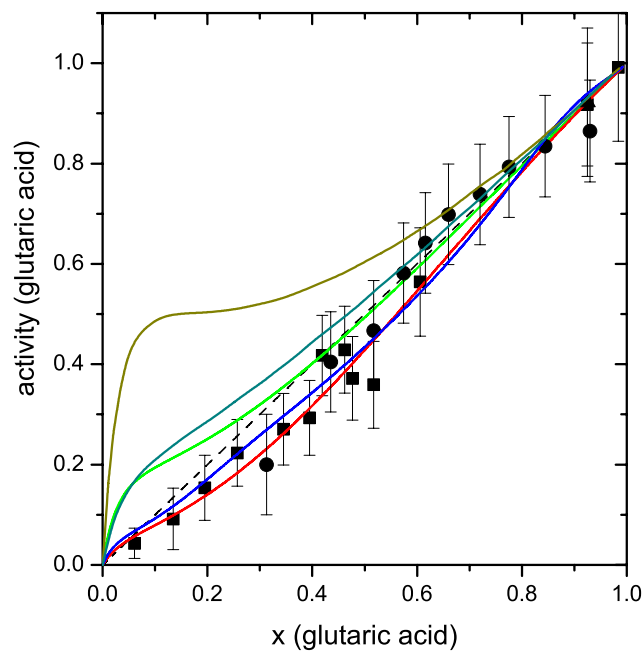

Fig. 2. Glutaric acid activity versus mole fraction of glutaric acid. Data at $T=290.9 \mathrm{~K}: \mathbf{\square}, T=281.3 \mathrm{~K}: \boldsymbol{\bullet}, T=303.2 \mathrm{~K}: \boldsymbol{\Delta}$. Dotted line: Raoult's law; Dark yellow line: UNIFAC Dortmund parameterization taken from Koponen et al. (2007); Dark cyan line: van Laar parmeterization by Koponen et al. (2007); Green line: UNIFAC parameterization by Ming and Russell (2002); Blue line: parameterization by Clegg and Seinfeld (2006a); Red line: UNIFAC parameterization by Peng et al. (2001). Mole fractions are on the basis of undissociated glutaric acid. * The Eqs. (5a) and (b) of Clegg and Seinfeld (2006a) contain several errors leading to large deviations especially for malonic acid. The coefficients given in Table 4 of Clegg and Seinfeld (2006a) are correct as they were estimated with the correct expressions (personal communication with Simon Clegg). The correct expressions are given in the Appendix A.

Accepting UNIFAC-Peng for the activity, neglecting any temperature dependence of the activity and assuming a Clausius-Clapeyron relationship (Eq. 3) between vapor pressure, $p^{\mathrm{L}}$, and temperature, $T$, we may determine the vapor pressure of the pure solute, $p^{\circ, \mathrm{L}}\left(T^{\ominus}\right)$, at $T^{\ominus}=298.15 \mathrm{~K}$, and the enthalpy change of vaporization alternatively by using

$p^{\mathrm{L}}(T)=p^{\circ, \mathrm{L}}\left(T^{\ominus}\right) a^{(x)} \exp \left[-\frac{\Delta H_{\text {vap }}^{\ominus}}{R}\left(\frac{1}{T}-\frac{1}{T^{\ominus}}\right)\right]$,

where, $a^{(x)}$ is the mole fraction based activity, i.e. $a^{(x)}=1$ for the pure organic acid, and $\Delta H_{\text {vap }}^{\ominus}$ is the standard enthalpy change of vaporization. A fit to all the data yields a vapor pressure of the supercooled melt of $p^{\circ, \mathrm{L}}\left(T^{\ominus}\right)=(9.3 \pm 2.7) \times 10^{-4} \mathrm{~Pa}$ and an enthalpy change of vaporization of $\Delta H_{\text {vap }}^{\ominus}=99 \pm 8 \mathrm{~kJ} \mathrm{~mol}^{-1}$, see Fig. 3. Inspection of Fig. 3 shows that all data points agree with the UNIFAC Peng paramterization within error.

Both, $p^{\circ, \mathrm{L}}\left(T^{\ominus}\right)$ and $\Delta H_{\text {vap }}^{\ominus}$ determined with a fit of all data to Eq. (3) (using the UNIFAC-Peng parameterization to convert concentrations to activity) agree within error with the ones determined directly from the experimental data. We assume that the value obtained considering all available data

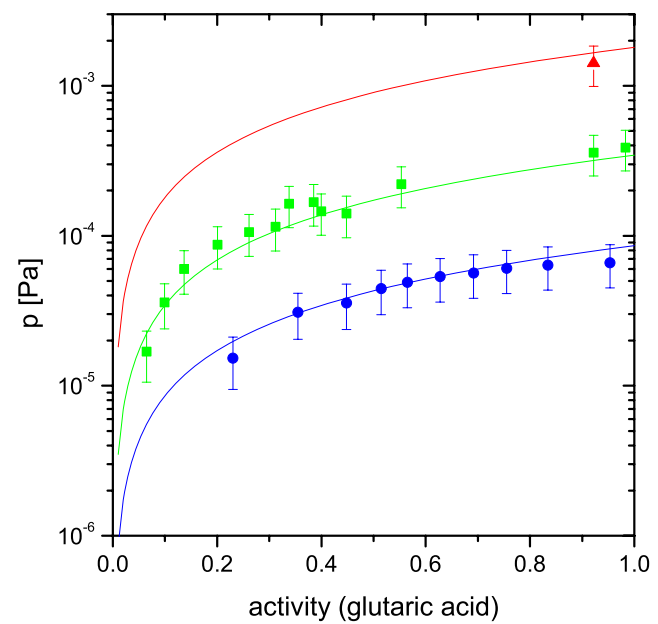

Fig. 3. Vapor pressure from evaporation rates of glutaric acid plotted versus activity from UNIFAC-Peng (Peng et al., 2001). Data at $T=281.3 \mathrm{~K}: \bullet, T=290.9 \mathrm{~K}: \square, T=303.2 \mathrm{~K}: \Delta$. Lines are the results of one fit to all data using Eq. (3).

based on Eq. (3) is more accurate and will be used from now on.

We measured the evaporation rates of solid glutaric acid particles after efflorescence of liquid particles under very dry conditions. An example of such a measurement is shown in Fig. 4.

The rates shown in the figure are deduced from the optical resonance spectra as described by Zardini et al. (2009, 2010). The precision of the vapor pressures obtained when sizing solid particles is lower compared to those of liquid droplets (Zardini et al., 2009, 2010), because of the uncertainties associated with deducing equivalent radius changes from optical resonance spectra for non-spherical particles. Also, the evaporation rate of a non-spherical particle may exceed that of an equivalent sphere particle because of its larger surface area. More important, however, is a feature of the evaporation of effloresced solids in the micrometer size range obvious when studying data as shown in Fig. 4: after efflorescence the particles in our experiments typically evaporate at a rate which is more than an order of magnitude faster compared to the rate after a day of evaporation (see Zardini et al., 2009, 2010, or Fig. 9 for another example). Using the data of Fig. 4, the initial rate (blue dashed line) corresponds to a vapor pressure over the solid of $p^{\circ, \mathrm{S}}(290.9 \mathrm{~K})=(2.6 \pm 0.9) \times 10^{-4} \mathrm{~Pa}$, which agrees within error with the vapor pressure of the supercooled melt at this temperature of $p^{\circ, \mathrm{L}}(290.9 \mathrm{~K})=(3.4 \pm 1.0) \times 10^{-4} \mathrm{~Pa}$. But almost a day later the vapor pressure of the particle has dropped to $p^{\circ, \mathrm{S}}(290.9 \mathrm{~K})=(1.4 \pm 0.5) \times 10^{-5} \mathrm{~Pa}$ (orange dashed line). Since equilibrium thermodynamics requires the vapor pressure of the saturated solution to be the same as the one of the corresponding crystalline solid at the same temperature, we can compare these pressures. 


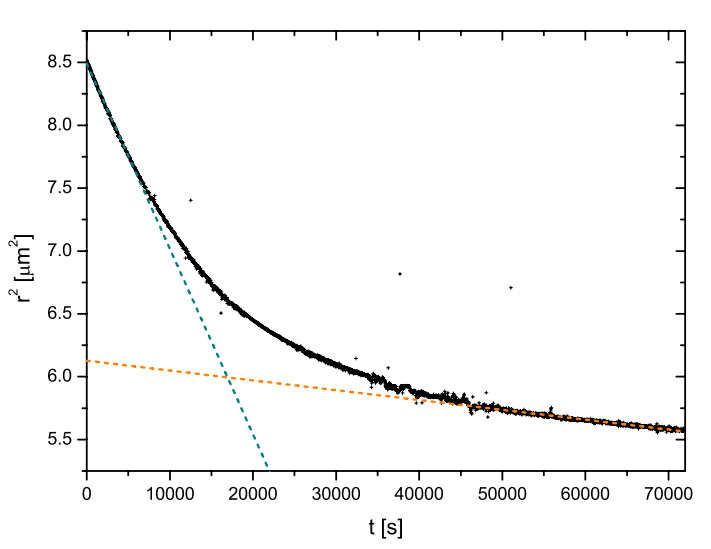

Fig. 4. Evaporation rate $\frac{d r^{2}}{d t}$ of a solid glutaric acid particle (of initial size $2.91 \mu \mathrm{m}$ equivalent radius) after efflorescence under dry conditions $(\mathrm{RH}<1 \%)$ at $T=290.9 \mathrm{~K}$. The rate changes with time from an initial rate (blue dashed line) of $\frac{d r^{2}}{d t}=-1.48 \times 10^{-4} \mu \mathrm{m}^{2} \mathrm{~s}^{-1}$ to a rate of $\frac{d r^{2}}{d t}=-7.82 \times 10^{-6} \mu \mathrm{m}^{2} \mathrm{~s}^{-1}$ (orange dashed line) after almost a day of evaporation. (Outliers in the radius data are due to noise in the optical resonance spectra for non-spherical particles (Zardini et al., 2009, 2010) and do not imply sudden changes in radius.)

The concentration of the saturated solution of glutaric acid at $T=298.15 \mathrm{~K}$ is $x^{\mathrm{sat}}(298.15 \mathrm{~K})=0.136$ (Marcolli et al., 2004), taking the temperature dependence of solubility into account (Apelblat and Manzurola, 1989) at $T=290.9 \mathrm{~K}$ it is $x^{\text {sat }}(290.9 \mathrm{~K})=0.095$. This allows us to calculate the vapor pressure of the saturated solution $p^{\mathrm{sat}, \mathrm{L}}(290.9 \mathrm{~K})$ from $p^{\circ, \mathrm{L}}(290.9 \mathrm{~K})$ and the activity (extrapolated from the measurements) at $x^{\text {sat }}$ which is $a^{(x) \text {,sat }} \simeq 0.06$, using Eq. (3), see Fig. 2. The resulting vapor pressure of the saturated solution, $p^{\text {sat, } \mathrm{L}}(290.9 \mathrm{~K})=(2.1 \pm 0.7) \times 10^{-5} \mathrm{~Pa}$, agrees within error with the one obtained for the solid particle after one day of evaporation. Thus, we conclude that the particle after efflorescence contains a substantial amount of material which evaporates at higher rate than the stable solid. For glutaric acid, we indeed have indication of aqueous inclusions from hygroscopicity cycles performed on particles in the EDB (see Fig. 5 of Zardini et al., 2008). During the main efflorescence step only a part of the water is lost. Subsequent continuous water loss over a broad RH range is observed until the hygroscopicity cycles close. Because the same initial mass is reached for several subsequent cycles we can exclude irreversible mass loss (e.g. by evaporation) as explanation for this effect. The amount of crystalline material present in the effloresced particle initially may be estimated from the extrapolation of the orange dashed line in Fig. 4 to the start of the experiment. This implies that about $60 \%$ of the mass of the solid after efflorescence were crystalline and $40 \%$ were aqueous inclusions. The implications of this observation will be discussed further below. One immediate consequence for our own measurements is that if these ratios are representa-

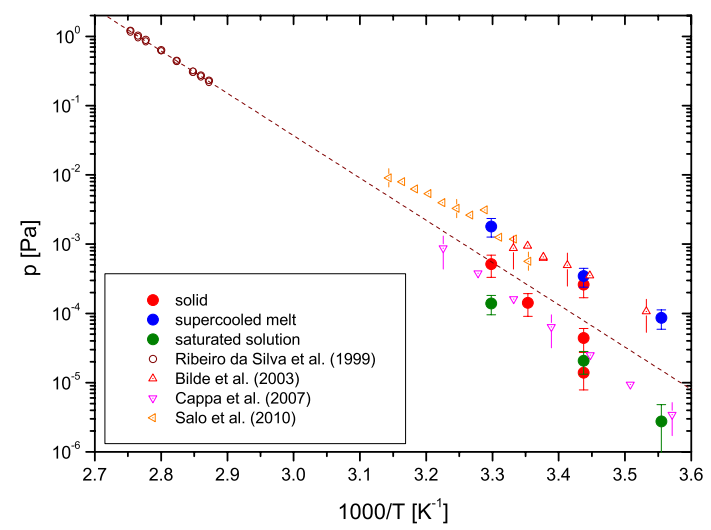

Fig. 5. Vapor pressure from evaporation rates of glutaric acid versus temperature. Our measurements for the solid, (supercooled) liquid, and saturated solution states are plotted as indicated in the key. For comparison, a selection of literature data is plotted as well. Dotted line: extrapolation of high temperature data (Ribeiro da Silva et al., 1999) to ambient temperatures. Note that the two data points of the solid at the highest and lowest vapor pressures at $1 / T=3.44 \times 10^{-3} \mathrm{~K}^{-1}$ originate from the same particles, but at different times after efflorescence, see Fig. 4 and discussion in the text.

tive also for larger particles, the time needed before measuring the relevant vapor pressure of the crystalline solid exceeded those we often used. This becomes evident when plotting our data versus temperature as shown in Fig. 5. As discussed, the solid vapor pressures at $T=290.9 \mathrm{~K}$ span a considerable range, an additional data point measured with a different particle of $9.4 \mu \mathrm{m}$ radius lays somewhere in between.

We calculate the enthalpy change of sublimation, from the inferred vapor pressures for the saturated solutions of $\Delta H_{\text {sub }}^{\ominus}=(122 \pm 8) \mathrm{kJ} \mathrm{mol}^{-1}$. This procedure is most likely the more accurate determination of the enthalpy change of sublimation compared to using the data of the solids, because the ambiguities associated with the solid state do not arise. While the associated error does not allow to precisely determine the resulting enthalpy change of fusion $\Delta H_{\text {fus }}^{\ominus}=\Delta H_{\text {sub }}^{\ominus}-\Delta H_{\text {vap }}^{\ominus}, \Delta H_{\text {fus }}^{\ominus}=(23 \pm 11) \mathrm{kJ} \mathrm{mol}^{-1}$ is at least consistent with data reported in the literature, i.e. $(17.6 \pm 1.1) \mathrm{kJ} \mathrm{mol}^{-1}$ (Roux et al., 2005). Note that thermodynamics requires $\Delta H_{\text {fus }}^{\ominus}$ to be positive.

Figure 5 shows that our data of most solid particles (see also Table 2) seem to agree within error with those of Cappa et al. (2007) but disagree in both enthalpy and absolute pressure with those of Bilde et al. (2003) and Salo et al. (2010). Their data seem to agree much better with our data for the supercooled liquid, see Sect. 4. For glutaric acid our vapor pressures of both, saturated solution and solid, agree within error, for the particle with the smallest radius and longest residence time of evaporation while the ones of the other solid particles are significantly larger. Since the lowest measured 


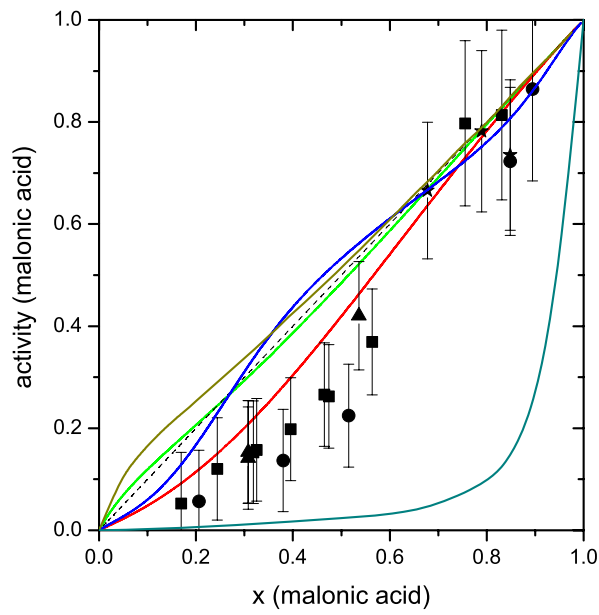

Fig. 6. Malonic acid activity versus mole fraction: Data at $T=273.8 \mathrm{~K}: \star, T=281.0 \mathrm{~K}: \bullet, T=291.0 \mathrm{~K}: \mathbf{\square}, T=300.0 \mathrm{~K}: \mathbf{\Delta}$. Data from Zardini et al. (2006). Dotted line: Raoult's law; Dark yellow line: UNIFAC Dortmund parameterization taken from Koponen et al. (2007); Dark cyan line: van Laar parmeterization by Koponen et al. (2007); Green line: UNIFAC parameterization by Ming and Russell (2002); Blue line: parameterization by Clegg and Seinfeld (2006a)*; Red line: UNIFAC parameterization by Peng et al. (2001). Mole fractions are on the basis of undissociated malonic acid. ${ }^{*}$ See footnote to Fig. 2.

vapor pressure of the solid is consistent with equilibrium thermodynamics, we take this one as the one of the thermodynamically stable crystalline state.

\subsection{Malonic acid}

For malonic acid, we measured evaporation rates at 4 different temperatures $(273.8 \mathrm{~K}, 281.0 \mathrm{~K}, 291.0 \mathrm{~K}$ and $300.0 \mathrm{~K})$ spanning a range in $\mathrm{RH}$ from 8 to $81 \%$. The data have been published previously (Zardini et al., 2006). In Fig. 6 we compare the measured activities with model predictions.

As with glutaric acid, UNIFAC-Peng seems to represent our data best, although our data show consistently lower malonic acid activities at lower concentrations of malonic acid. While the van Laar parameterization of Koponen et al. (2007) shows low activity for the lower concentrations it by far exceeds the deviation from Raoult's law compared to the experimental activities. The parameterizations of Clegg and Seinfeld (2006a), Ming and Russell (2002) and UNIFACDortmund (Koponen et al., 2007) are close to Raoult's law and do not describe the deviations from ideal behavior found in our data at lower concentrations of malonic acid. We do not observe any systematic dependence of activity on temperature and conclude that the temperature dependence of activity is significantly smaller in the range between $274 \mathrm{~K}$ and $300 \mathrm{~K}$ than the error associated with our measurements.

Since none of our aqueous particles did effloresce in the EDB even under very dry conditions, we injected solid mal-

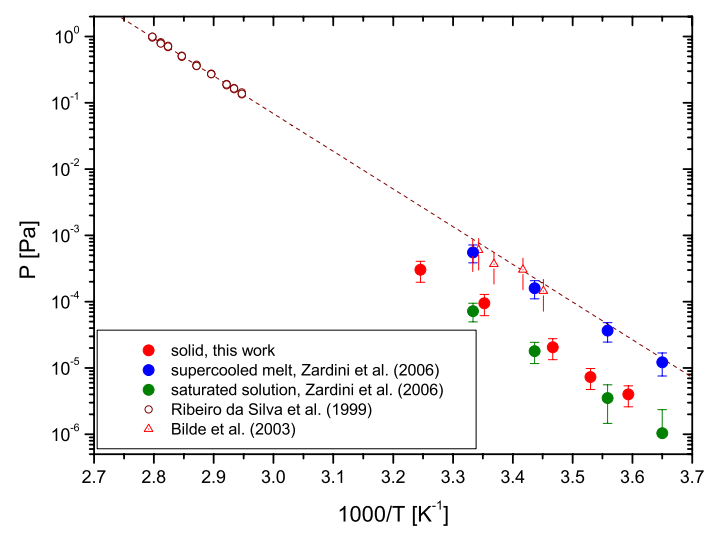

Fig. 7. Malonic acid vapor pressures versus temperature, solid symbols: this work and Zardini et al. (2006); Open symbols: literature data as indicated in the figure. Dotted line: extrapolation of high temperature data (Ribeiro da Silva et al., 1999) to ambient temperatures.

onic acid particles into the EDB to measure the evaporation rate of solid particles. The resulting vapor pressures together with literature data and those of the supercooled melt extrapolated from the aqueous solution measurements are shown in Fig. 7, see also Table 2. Our vapor pressures of the solid malonic acid are substantially lower than those of Bilde et al. (2003) as well as those of Ribeiro da Silva et al. (1999) extrapolated to lower temperatures, however, both agree with our vapor pressures of the supercooled melt. This is an indication that both may have measured the supercooled melt instead of the crystalline solid, as was first speculated by Zardini et al. (2006) and later supported by Koponen et al. (2007) and Riipinen et al. (2007). If we calculate the vapor pressure of the saturated solution from the vapor pressures of the aqueous solutions, using solubility, $x^{\text {sat }}(298.15 \mathrm{~K})=0.215$ (Marcolli et al., 2004) and its temperature dependence (Apelblat and Manzurola, 1987) as well as the activity coefficients of UNIFAC-Peng, the resulting vapor pressures agree within error with the measured pressure of the solid (see Fig. 7), proving the consistency of our measurements of aqueous solutions and the solids. The fact that the vapor pressures of the saturated solutions seem to be slightly lower compared to those of the solid, may be attributed to the previously discussed uncertainties with interpreting evaporation rates of non-spherical particles.

Fitting our vapor pressures of the solid malonic acid to a Clausius-Clapeyron relationship yields an enthalpy change of sublimation of $\Delta H_{\text {sub }}^{\ominus}=(107 \pm 4) \mathrm{kJ} \mathrm{mol}^{-1}$, matching that of the saturated solutions yielding $\Delta H_{\text {sub }}^{\ominus}=(111 \pm 4) \mathrm{kJ} \mathrm{mol}^{-1}$. Previously, we derived an enthalpy change of vaporization for the data of the supercooled melt: $\Delta H_{\text {vap }}^{\ominus}=(100 \pm 17) \mathrm{kJ} \mathrm{mol}^{-1}$ (Zardini et al., 2006). If we combine the data of Bilde et al. (2003), $\Delta H_{\text {vap }}^{\ominus}=(92 \pm 15) \mathrm{kJ} \mathrm{mol}^{-1}$, and our data of the supercooled melt we obtain a best estimate for the enthalpy change of 


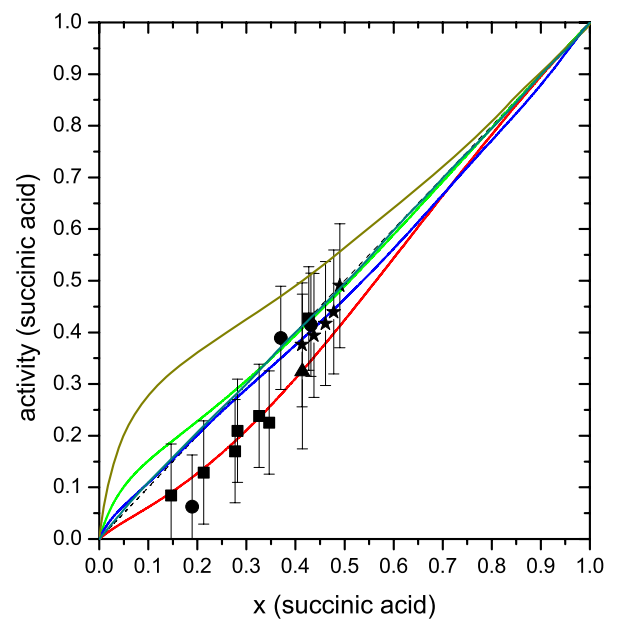

Fig. 8. Succinic acid activity versus mole fraction. Data at $T=278.8 \mathrm{~K}: \star, T=283.2 \mathrm{~K}: \bullet, T=290.9 \mathrm{~K}: \mathbf{\square}, T=298.4 \mathrm{~K}: \boldsymbol{\Delta}$. Dotted line: Raoult's law; Dark yellow line: UNIFAC Dortmund parameterization taken from Koponen et al. (2007); Dark cyan line: van Laar parmeterization by Koponen et al. (2007); Green line: UNIFAC parameterization by Ming and Russell (2002); Blue line: parameterization by Clegg and Seinfeld (2006a)*; Red line: UNIFAC parameterization Peng et al. (2001). Mole fractions are on the basis of undissociated succinic acid. ${ }^{*}$ See footnote to Fig. 2.

vaporization of $\Delta H_{\text {vap }}^{\ominus}=(96 \pm 11) \mathrm{kJ} \mathrm{mol}^{-1}$. Using Eq. (3), we obtain with this value $p^{\circ, L}\left(T^{\ominus}\right)=(4.3 \pm 1.5) \times 10^{-4} \mathrm{~Pa}$ instead of $p^{\circ, L}\left(T^{\ominus}\right)=(3.2 \pm 1.2) \times 10^{-4} \mathrm{~Pa}$ (Zardini et al., 2006). We consider this new value as the best estimate of the vapor pressure of the supercooled melt at $T^{\ominus}=298.15 \mathrm{~K}$ on the basis of our data. The enthalpy change of fusion determined from these measurements again bears a considerable uncertainty, but using the enthalpy change of sublimation from the data of the saturated solutions yields $\Delta H_{\text {fus }}^{\ominus}=\Delta H_{\text {sub }}^{\ominus}-\Delta H_{\text {vap }}^{\ominus}=(15 \pm 12) \mathrm{kJ} \mathrm{mol}^{-1}$, which is lower but still consistent with differential calorimetry data, i.e. (23.1 \pm 1.2$) \mathrm{kJ} \mathrm{mol}^{-1}$ (Hansen and Beyer, 2004).

\subsection{Succinic acid}

Since succinic acid has a significantly lower solubility than the acids considered first, we were only able to supersaturate aqueous succinic acid particles to a relative humidity of about $50 \%$ before efflorescence occurred. This restricted the concentration range of the aqueous solutions we could study from dilute solutions to a mole fraction of succinic acid of about 0.5 . Hence, the uncertainty in the determination of the vapor pressure for the supercooled succinic acid is increased relative to the more soluble acids. This determination is based on assuming Raoult's law for extrapolating the data at $x_{\text {succinic }} \approx 0.5$ to $x_{\text {succinic }}=1$. We measured evaporation rates at four temperatures and determined the vapor pressures for the supercooled melts analogously to the procedure outlined for glutaric acid, using data at concentrations larger

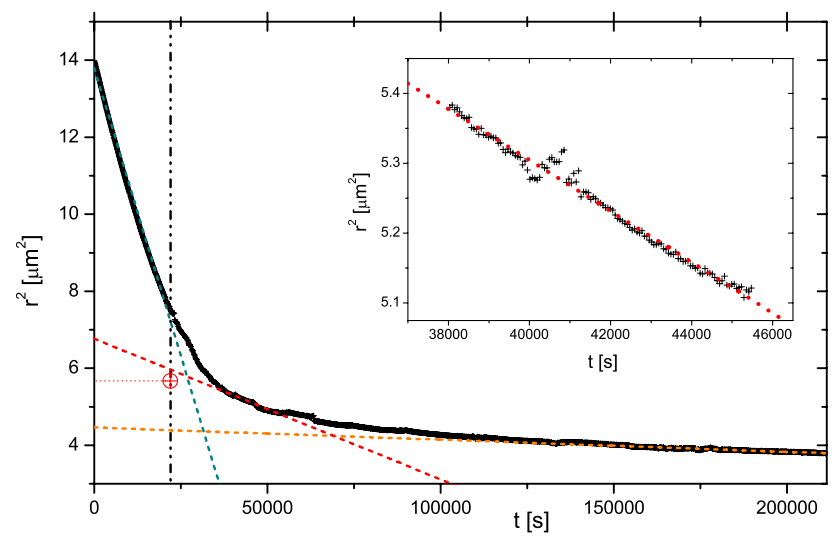

Fig. 9. Evaporation rate of a succinic acid particle at $T=298.5 \mathrm{~K}$, $\mathrm{RH} \cong 50 \%$. Black crosses are the data obtained from optical resonance spectroscopy (Zardini et al., 2009, 2010). The particle effloresces at $t=22000 \mathrm{~s}$ (indicated by the vertical dasheddotted line), the phase transition is determined from 2-dimensional angular scattering data, not shown here (for details see Zardini et al., 2009, 2010). Linear fits to data points for the liquid state yield $\frac{d r^{2}}{d t}=2.99 \times 10^{-4} \mu \mathrm{m}^{2} \mathrm{~s}^{-1}$ (dashed blue line). For the solid, the data between $38 \mathrm{ks}$ and $46 \mathrm{ks}$ yield a rate of $\frac{d r^{2}}{d t}=3.65 \times 10^{-5} \mu \mathrm{m}^{2} \mathrm{~s}^{-1}$ (dashed red line, see inset of the figure for details) and for the data between $150 \mathrm{ks}$ and $213 \mathrm{ks}$ we obtain a rate of $\frac{d r^{2}}{d t}=3.16 \times 10^{-6} \mu \mathrm{m}^{2} \mathrm{~s}^{-1}$ (dashed orange line), see text for discussion. The red circle marks the $r^{2}$ to which the particle would shrink if it lost all the water upon efflorescence immediately, see text.

than $x=0.35: \quad p^{\circ, \mathrm{L}}(278.8 \mathrm{~K})=(6.9 \pm 2.2) \times 10^{-5} \mathrm{~Pa}$, $p^{\circ, \mathrm{L}}(283.2 \mathrm{~K})=(1.4 \pm 0.4) \times 10^{-4} \mathrm{~Pa}, \quad p^{\circ, \mathrm{L}}(290.9 \mathrm{~K})=$ $(6.7 \pm 2.0) \times 10^{-4} \mathrm{~Pa}, \quad$ and $\quad p^{\circ, \mathrm{L}}(298.4 \mathrm{~K})=(1.3 \pm 0.4)$ $\times 10^{-3} \mathrm{~Pa}$. A fit to Clausius-Clapeyron yields the enthalpy change of vaporization of $\Delta H_{\text {vap }}^{\ominus}=(106 \pm 8) \mathrm{kJ} \mathrm{mol}^{-1}$ and $p^{\circ, \mathrm{L}}\left(T^{\ominus}\right)=(1.7 \pm 0.5) \times 10^{-3} \mathrm{~Pa}$. The concentration dependence of activity indicate that again the UNIFAC-Peng parameterization of activity versus concentration agrees best to our data, see Fig. 8. All parameterizations indicate that assuming Raoult's law for concentrations greater than $x_{\text {succinic }} \simeq 0.5$ is justified.

Solid particles from both, effloresced aqueous particles and particles injected as solids, showed considerable variation in vapor pressure. An example of the raw data of an evaporating aqueous succinic acid particle is shown in Fig. 9. The particle effloresced during the measurement with the RH and temperature constant at ca. $50 \%$ and $298.5 \mathrm{~K}$, respectively.

The rate of evaporation, $\frac{d r^{2}}{d t}$ see Eq. (1), does not reduce drastically after the supersaturated aqueous solution droplet effloresced at $t=22 \mathrm{ks}$, but it takes more than a day for the particle with a radius of about $2.75 \mu \mathrm{m}$ at the time of efflorescence to show a constant rate in $r^{2}$ indicative of a stable composition. This appears to be qualitatively similar to the 
solid glutaric acid evaporation shown in Fig. 4. However, there is one important difference: the concentration of the aqueous particle before efflorescence is only $x_{\text {succinic }}=0.46$, which means that a substantial amount of water is present within the particle after efflorescence. If this water would evaporate immediately upon crystallization of the supersaturated aqueous solution, we should observe a distinct stepwise reduction in radius, which is absent from the data of Fig. 9. The equivalent radius change expected if all water were lost to the gas phase immediately upon efflorescence is $\Delta r=0.36 \mu \mathrm{m}$, or from an $r^{2}=7.51 \mu \mathrm{m}^{2}$ in Fig. 9 to $r^{2}=5.67 \mu \mathrm{m}^{2}$, marked as red circle. As shown in the inset of Fig. 9, the vapor pressure at $T=298.5 \mathrm{~K}$ deduced from an apparently constant rate $20 \mathrm{ks}$ after the efflorescence took place, yields a vapor pressure for the solid of $p^{\circ, \mathrm{S}}(298.5 \mathrm{~K})=(7.4 \pm 2.6) \times 10^{-5} \mathrm{~Pa}$. The extrapolation of this line to the time of efflorescence yields a radius, which is close to the one estimated for an instantaneous water loss. However, the vapor pressure after another day of evaporation settles to a value one order of magnitude lower, i.e. to $p^{\circ, \mathrm{S}}(298.5 \mathrm{~K})=(6.4 \pm 2.6) \times 10^{-6} \mathrm{~Pa}$ (orange dashed line in Fig. 9). Comparing these vapor pressures with the one of the saturated solution, $p^{\text {sat, } \mathrm{L}}(298.5 \mathrm{~K})=(1.3 \pm 0.6) \times 10^{-5} \mathrm{~Pa}$, calculated from solubility, $x^{\text {sat }}(298.15 \mathrm{~K})=0.014$ (Apelblat and Manzurola, 1987), the corresponding UNIFAC-Peng activity, $a^{(x) \text {,sat }}=0.01$, and the pressure of the supercooled melt, $p^{\circ, \mathrm{L}}(298.5 \mathrm{~K})=(1.3 \pm 0.4) \times 10^{-3} \mathrm{~Pa}$, shows that the lower vapor pressure agrees within error with those of the saturated solution, which proves that it takes a significant time to evaporate material (solvent inclusions and defective crystal structures) that has not crystallized to the thermodynamically stable crystalline solid. It is interesting to note that in contrast to solid glutaric acid particles, evaporating solid succinic acid particles showed sudden changes in the optical resonances spectra (Zardini et al., 2009, 2010), which we interpreted as rearrangements within the particle upon evaporation, but could also be connected to the sudden exposure of solvent inclusions to the gas phase upon evaporation.

Figure 10 shows the vapor pressures in comparison to literature data. All literature data shown (Bilde et al., 2003; Cappa et al., 2007; Salo et al., 2010) are measurements of the vapor pressure of the solid succinic acid and agree within error with each other as well as with the extrapolation from high temperature data (Davies and Thomas, 1960). Our pressures for the supercooled melt are larger than the literature data for the pressures of the solid and show a smaller change in enthalpy, as expected. The two data points of the solid at $1 / T=3.35 \times 10^{-3} \mathrm{~K}^{-1}$ illustrate again the change in evaporation rate with time after the efflorescence, see Fig. 9 and discussion above. It is very interesting to note that our data of the solid vapor pressure immediately after efflorescence agree well with all literature data. However, our vapor pressure after the particles were allowed to evaporate for another 1.5 days with a corresponding reduction in volume of about $40 \%$ relative to the initial one, is about one order of magni-

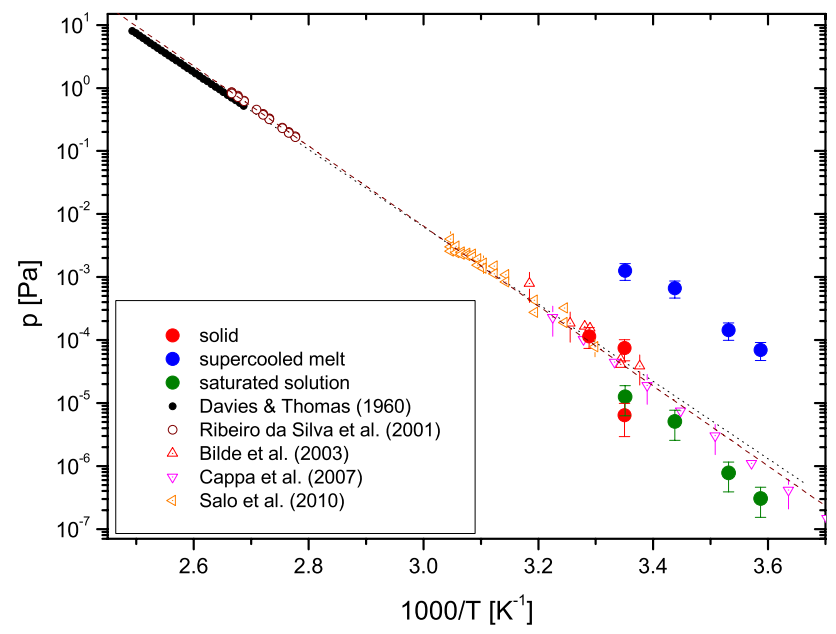

Fig. 10. Succinic acid vapor pressure versus temperature. Solid symbols: this work; Open symbols: literature data as indicated in the figure; Dotted black line: extrapolation of high temperature data Davies and Thomas (1960) to ambient temperatures, dashed wine line: extrapolation of high temperature data Ribeiro da Silva et al. (2001). Note that the two data points of the solid at $1 / T=3.35 \times 10^{-3} \mathrm{~K}^{-1}$ originate from the same particle, but at different times after efflorescence, see Fig. 9 and discussion in the text.

tude lower. It agrees with the independently measured one of the saturated solution at this temperature as required in thermodynamics equilibrium. Thus, we may speculate that all solids studied in the literature did not consist of the thermodynamically stable crystalline solid, but contained amorphous material and/or material with a high number of crystal defects.

Because of the spread in solid vapor pressure data due to different defect numbers and possibly also solvent inclusions, we are not able to deduce an enthalpy change of sublimation for succinic acid, from the solid data. We used the data of the saturated solutions to determine the enthalpy change of sublimation, which is: $\left(\Delta H_{\text {sub }}^{\ominus}=125 \pm 8 \mathrm{~kJ} \mathrm{~mol}^{-1}\right)$, consistent with what e.g. Cappa et al. (2007) have measured $\left(\Delta H_{\text {sub }}^{\ominus}=128 \pm 2 \mathrm{~kJ} \mathrm{~mol}^{-1}\right)$, although there pressures are significantly higher than ours. Thus, the enthalpy change of fusion is $\Delta H_{\text {fus }}^{\ominus}=19 \pm 11 \mathrm{~kJ} \mathrm{~mol}^{-1}$, this is also consistent with literature data $\left(\Delta H_{\text {fus }}^{\ominus}=26.5 \pm 2.3 \mathrm{~kJ} \mathrm{~mol}^{-1}\right.$ (Roux et al., 2005).

\subsection{Oxalic acid}

Oxalic acid is special when compared to the higher mass dicarboxylic acids because in this case oxalic acid dihydrate forms in aqueous solutions and the solids exhibit polymorphism (de Villepin et al., 1982; Tanaka, 1984; Camus et al., 1997). Vapor pressure data of aqueous solutions are of special importance here, since they do not require any knowledge about crystalline stoichiometry nor crystalline form. 


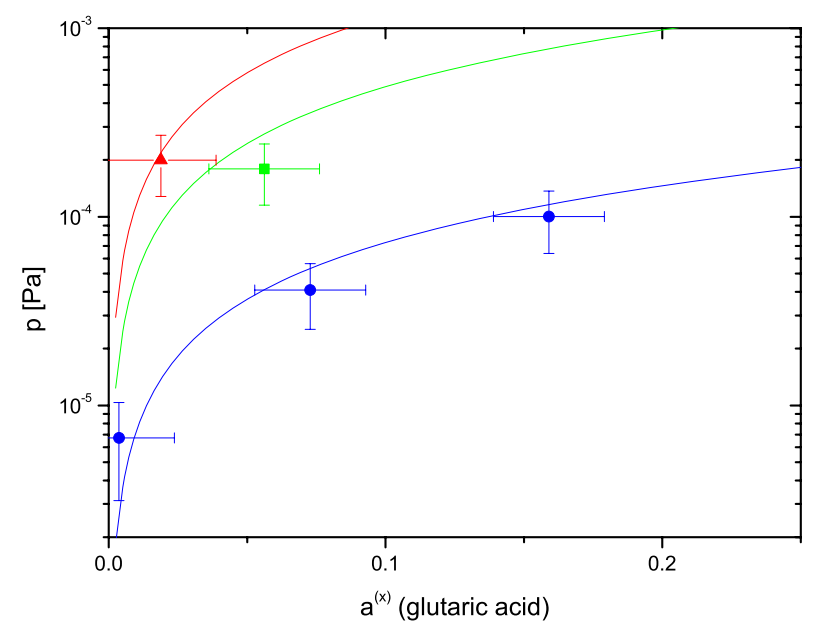

Fig. 11. Vapor pressure of oxalic acid plotted versus activity from UNIFAC-Peng (Peng et al., 2001). Data at $T=267.3 \mathrm{~K}$ : $\bullet$, $T=282.4 \mathrm{~K}: \square, T=289.9 \mathrm{~K}: \Delta$. Lines are the results of one fit to all data with Eq. (3).

We were not able to cover a broad range of concentrations with aqueous oxalic acid particles in our experiments, because the aqueous particles effloresced in our setup at RH lower than $68 \%$, and sometimes as high as $80 \% \mathrm{RH}$. This does not allow us to draw any definite conclusions on the activity of oxalic acid. Instead, we just took five measurements of dilute aqueous particles over a temperature range of $267 \mathrm{~K}<T<290 \mathrm{~K}$ and used UNIFAC-Peng for the activity to estimate the vapor pressures of the supercooled melt. Figure 11 shows the data and the fit to all data to obtain the vapor pressure of the supercooled oxalic acid at $T^{\ominus}=298.15 \mathrm{~K}$, $p^{\circ, \mathrm{L}}\left(T^{\ominus}\right)=(2.9 \pm 1.5) \times 10^{-2} \mathrm{~Pa}$, and the enthalpy change of vaporization: $\Delta H_{\mathrm{vap}}^{\ominus}=(79 \pm 15) \mathrm{kJ} \mathrm{mol}^{-1}$. It is difficult to estimate the error of the vapor pressure, $p^{\circ, \mathrm{L}}\left(T^{\ominus}\right)$, resulting from our measurement and this analysis, but we conservatively state it at $50 \%$ of the measured value.

As for the other dicarboxylic acids, we also measured the vapor pressure of solid oxalic acid particles. For oxalic acid the exact composition of the solid particles is not known nor is the polymorphic form. We expect that under dry conditions in our electrodynamic balance anhydrous oxalic acid forms. Raman spectra (not shown here) of the effloresced particle show no significant water content, but the spectral lines differ in intensity significantly from both the reference dihydrate spectra as well as from the ones of the anhydrous solids. Line positions of the effloresced particle and the dihydrate resemble best. From spectral evidence we can only state that the effloresced particles under dry conditions are dehydrated solids. Their vapor pressures as shown in Fig. 12 are however very close to those of the solution saturated with respect to the dihydrate, calculated from the supercooled melt vapor pressures and the solubility of the oxalic acid dihydrate (Apelblat and Manzurola, 1987).

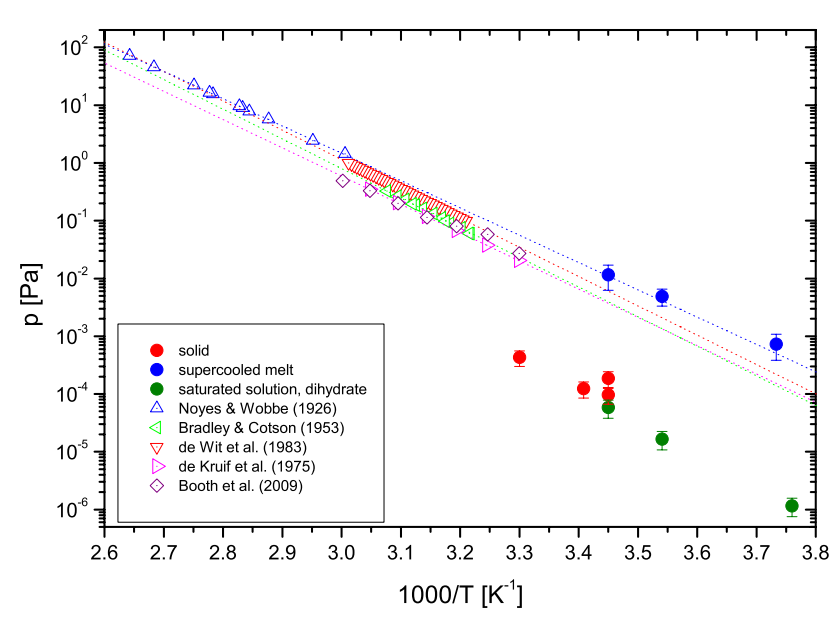

Fig. 12. Oxalic acid vapor pressure versus temperature. Our measurements for the solid, (supercooled) liquid, and saturated solution states are plotted as indicated in the key. For comparison a selection of literature data is plotted as well, together with extrapolations to ambient temperature.

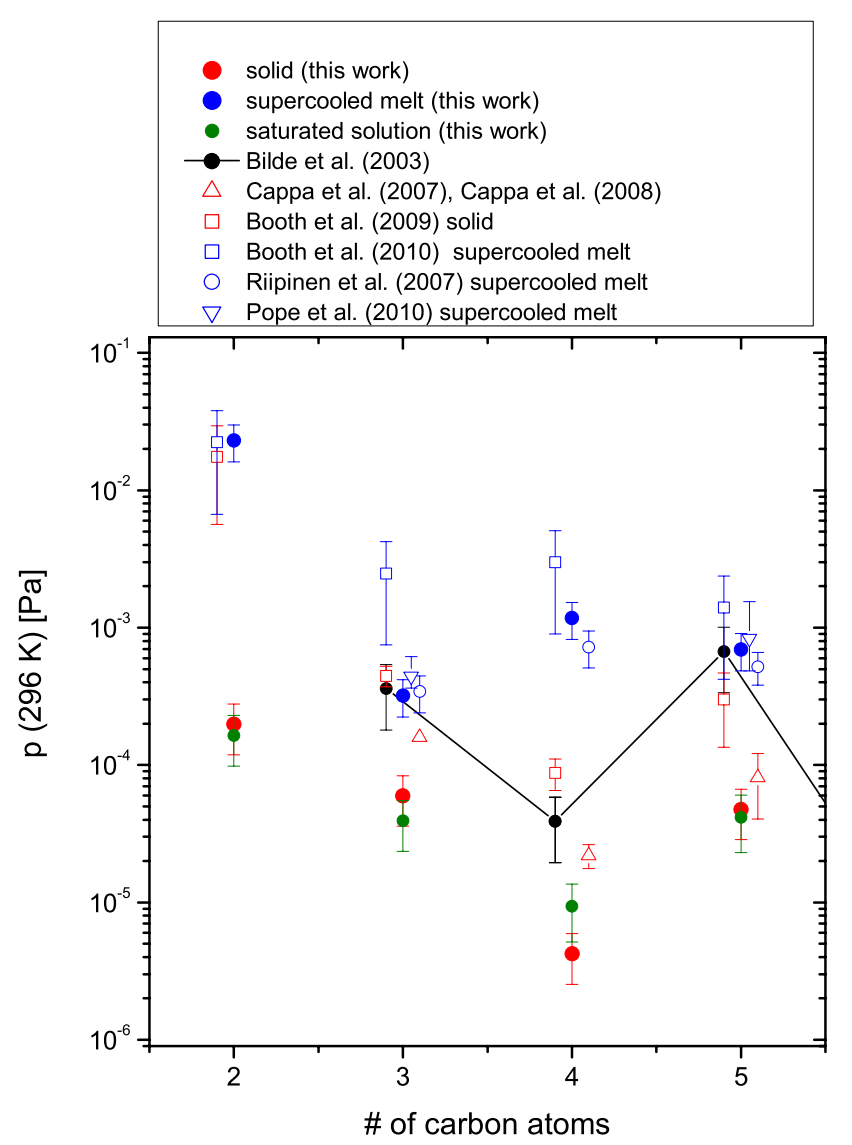

Fig. 13. Vapor pressures of dicarboxylic acids versus number of carbon atoms at $T=296 \mathrm{~K}$. Our data and selected literature data are plotted as indicated in the figure. (For clarity literature data are shifted slightly in carbon number). 
Table 3. Comparison of room temperature data $(T=298.15 \mathrm{~K})$ of vapor pressures for the short chain dicarboxylic acids. The upper half of the table shows data originally obtained at room temperature or below, the lower half data measured at higher temperatures and extrapolated to room temperature.

\begin{tabular}{|c|c|c|c|c|c|}
\hline Reference & $T$ range $^{\mathrm{a}}(\mathrm{K})$ & oxalic $(\mathrm{Pa})$ & malonic $(\mathrm{Pa})$ & succinic $(\mathrm{Pa})$ & glutaric $(\mathrm{Pa})$ \\
\hline this work (supercooled melt) & $266-303$ & $(2.9 \pm 1.5) \times 10^{-2}$ & $(4.3 \pm 1.5) \times 10^{-4}$ & $(1.7 \pm 0.5) \times 10^{-3}$ & $(9.3 \pm 2.8) \times 10^{-4}$ \\
\hline this work (saturated solution) ${ }^{b}$ & $266-303$ & $(2.1 \pm 1.0) \times 10^{-4}$ & $(5.3 \pm 1.9) \times 10^{-5}$ & $(1.5 \pm 0.8) \times 10^{-5}$ & $(5.6 \pm 1.8) \times 10^{-5}$ \\
\hline this work (solid) & $266-303$ & $(2.5 \pm 0.9) \times 10^{-4}$ & $(8.0 \pm 2.9) \times 10^{-5}$ & $(6.0 \pm 2.1) \times 10^{-6}$ & $(4.8 \pm 1.6) \times 10^{-5}$ \\
\hline Tao and McMurry (1989) (solid) & $263-323$ & - & - & - & $(1.04 \pm 0.16) \times 10^{-3}$ \\
\hline Bilde and Pandis (2001) (solid) & $290-300$ & - & - & - & $(7.5 \pm 3.7) \times 10^{-4}$ \\
\hline Bilde et al. (2003) (solid) & $290-314$ & - & $(5.3 \pm 2.7) \times 10^{-4}$ & $(4.6 \pm 2.3) \times 10^{-5}$ & $(8.8 \pm 4.4) \times 10^{-4}$ \\
\hline Chattopadhyay and Zieman (2005) (solid) & $276-302$ & - & - & $1.37 \times 10^{-4}$ & $4.04 \times 10^{-4}$ \\
\hline Riipinen et al. (2006) (supercooled melt) & 298 & - & - & $1.0 \times 10^{-3}$ & - \\
\hline Koponen et al. (2007) (supercooled melt) & $297.7-301.2$ & - & $7.3 \times 10^{-4}$ & $9.9 \times 10^{-4}$ & $7.1 \times 10^{-4}$ \\
\hline Riipinen et al. (2007) (supercooled melt) & $293-299$ & - & $(4.9 \pm 1.0) \times 10^{-4}$ & - & - \\
\hline Pope et al. (2010) (supercooled melt) & $280-304$ & - & $\left(6.7_{-1.2}^{+2.6}\right) \times 10^{-4}$ & - & $\left(11.2_{-4.7}^{+9.6}\right) \times 10^{-4}$ \\
\hline Cappa et al. (2008) (solid) & $313-358$ & - & $7.3 \times 10^{-4}$ & - & - \\
\hline Cappa et al. (2007) (solid) & $313-358$ & - & - & $(3.2 \pm 0.6) \times 10^{-5}$ & $(1.2 \pm 0.6) \times 10^{-4}$ \\
\hline Booth et al. (2009) (solid) & $303-333$ & $(2.15 \pm 1.19) \times 10^{-2}$ & $(5.73 \pm 1.14) \times 10^{-4}$ & $(1.13 \pm 0.47) \times 10^{-4}$ & $(4.21 \pm 1.66) \times 10^{-4}$ \\
\hline Booth et al. (2010) (supercooled melt) & $303-333$ & $(2.7 \pm 1.9) \times 10^{-2}$ & $(3.2 \pm 2.2) \times 10^{-3}$ & $(3.9 \pm 2.7) \times 10^{-3}$ & $(2.0 \pm 1.3) \times 10^{-3}$ \\
\hline Salo et al. (2010) (solid) & $299-328$ & - & - & $\left(6.4_{-1.8}^{+2.0}\right) \times 10^{-5}$ & $\left(8.5_{-2.2}^{+3.1}\right) \times 10^{-4}$ \\
\hline Noyes and Wobbe (1926) (solid) & $333-378$ & $\begin{array}{l}(3.1 \pm 0.1) \times 10^{-2} \\
\quad(\text { sublimated })\end{array}$ & - & - & - \\
\hline Bradley and Cotson (1953) (solid) & $311-325$ & $\begin{array}{l}1.2 \times 10^{-2}(\alpha \text {-form }) \\
2.2 \times 10^{-2}(\beta \text {-form })\end{array}$ & - & - & - \\
\hline de Kruif et al. (1975) (solid) & $303-328$ & $1.10 \times 10^{-2}(\alpha-$ form $)$ & & & \\
\hline de Wit et al. (1983) (solid) & $312-332$ & $1.9 \times 10^{-2}(\alpha$-form $)$ & - & - & - \\
\hline Davies and Thomas (1960) (solid) & $372-401$ & - & - & $4.1 \times 10^{-5}$ & - \\
\hline Ribeiro da Silva et al. (1999) (solid) & $339-363$ & - & $(6.7 \pm 1.9) \times 10^{-4}$ & - & $(2.5 \pm 1.3) \times 10^{-4}$ \\
\hline Ribeiro da Silva et al. (2001) (solid) & $360-375$ & - & - & $(3.6 \pm 2.8) \times 10^{-5}$ & - \\
\hline
\end{tabular}

${ }^{a}$ Temperature range of experimental data. ${ }^{b}$ Literature data for solubilities (Marcolli et al., 2004) were used for interpolating/extrapolating the vapor pressure of the measured aqueous solutions to those of the saturated solution, using the measured activities. Temperature dependence of water-solubilities were taken from Apelblat and Manzurola (1987) and Apelblat and Manzurola (1989).

The vapor pressures of the supercooled melt agree with the pressures Noyes and Wobbe (1926) measured for anhydrous oxalic acid which they prepared by condensation from the gas phase. They describe their sublimed oxalic acid as "quite lumpy" and we speculate that it may have been an amorphous solid, which would explain the agreement with our supercooled melt vapor pressures. All other literature data are vapor pressures of the anhydrous crystalline solid and they are approximately a factor of 2 to 5 lower as compared to our data of the supercooled melt.

\section{Discussion}

Let us first discuss our results with respect to the solute activities. Common to the three dicarboxylic acids (malonic, succinic and glutaric), for which we were able to directly derive solute activity data from our experiments, is that they all deviate to lower activities relative to Raoult's law at dilute to moderate concentrations. Regarding the parameterizations for dicarboxylic acid activities available in the literature our data agree within error for all three acids with the UNIFAC parameterization of Peng et al. (2001), but deviate significantly from the models of Clegg and Seinfeld (2006a), Ming and Russell (2002), UNIFAC-Dortmund (Koponen et al., 2007) and the van Laar parameterization of Koponen et al. (2007), except for glutaric acid, which is in agreement with the Clegg and Seinfeld (2006a) parameterization. Furthermore, there is no evidence for a temperature dependence of dicarboxylic acid activity in the investigated temperature range from $266 \mathrm{~K}$ to $303 \mathrm{~K}$ for all three dicarboxylic acids.

Table 3 shows our vapor pressure data $(T=298.15 \mathrm{~K})$ for the supercooled melt, the solid and the saturated solution and compares them to literature data. In addition, Fig. 13 shows a direct comparison with the data of Bilde et al. (2003) and other selected data at $296 \mathrm{~K}$ to facilitate the following discussion of the influence of the physical state of the aerosol on vapor pressure.

For malonic and glutaric acid our data of the solid vapor pressures are consistent with the TPD data (solid glutaric acid) as are the supercooled melt data with the EDB data of Pope et al. (2010) and the TDMA data (Bilde et al., 2003), if we assume the physical state of the aerosol in the TDMA experiments as supercooled melt. In the original work of Bilde et al. (2003) it was assumed that all dicarboxylic acids were solid particles, when in fact the odd acids most probably 
remained supercooled melt particles upon drying. Also, the more recent TDMA data of the supercooled melts (Koponen et al., 2007; Riipinen et al., 2007) agree within error with our measurements. The supercooled melt vapor pressures inferred from solid vapor pressures (e.g., Booth et al., 2010) are considerably higher compared to our and the TDMA data. This is most likely connected to a general remark we would like to make: vapor pressures of solid particles or bulk material is more difficult to investigate, because the solid may contain crystalline structures with a high number of defects, or even solvent inclusions in their assay. For solid succinic acid we were able to perform an experiment leading to a vapor pressure consistent with the one of the saturated solution. This vapor pressure over the solid is lower than any data reported in the literature. This may be an indication that literature data of solid succinic acid might be compromised by the presence of not well crystallized material, i.e. crystalline structures with a high defect number, or solvent inclusions.

The vapor pressure of supercooled oxalic acid is about two orders of magnitude larger than those of the other short chain dicarboxylic acids. Our data of the supercooled melt agree within error with both those of Noyes and Wobbe (1926) and Booth et al. (2010), those being only slightly higher compared to what has been measured as vapor pressures of oxalic acid in its anhydrous state. Figure 12 shows a good agreement between our values of the vapor pressure of the solid and the saturated solution of oxalic acid. Such a good agreement is however not expected since we determined the vapor pressure of the saturated oxalic acid dihydrate solution, which should be lower than the one of the dehydrated solid, that we measured for the effloresced particle. We do not have any explanation for this coincidence. At this stage, we can only state that such low vapor pressures of effloresced oxalic acid particles are consistent with observations from HTDMA experiments (Prenni et al., 2001; Mikhailov et al., 2009) where oxalic acid does not show any observable evaporation in contrast to e.g., glutaric acid. One hypothesis is that traces of ammonia present as impurities might decrease the evaporation rate of effloresced oxalic acid particles (Mensah et al., 2009).

Our data for the vapor pressures of the solid acids approach the values of the saturated solutions slowly with increasing time after efflorescence as required by equilibrium thermodynamics. The data of the supercooled melt show no even-odd alternation in vapor pressures, but the vapor pressures of the supercooled melts of the $\mathrm{C}_{3}$ to $\mathrm{C}_{5}$ dicarboxylic acids are the same within a factor of 4 and of a magnitude of $3 \times 10^{-4} \mathrm{~Pa}$ to $1 \times 10^{-3} \mathrm{~Pa}$ at $296 \mathrm{~K}$. The even-odd alternation is clearly evident in the vapor pressures of the solid $\mathrm{C}_{3}$ to $\mathrm{C}_{5}$ dicarboxylic acids, with the odd acids exhibiting higher vapor pressures. This is reflected in the melting temperatures of the acids (see Table 1), with the odd acids showing lower melting temperatures than the even ones. The fact that the acids show an alternation in vapor pressure as crystalline solids but not as supercooled melts is related to the solubili- ties of the acids, with the even acids being less soluble than their odd counterparts.

\section{Conclusions}

Considering the atmospheric implications of these findings, we conclude that gas/particle partitioning of the $\mathrm{C}_{3}$ to $\mathrm{C}_{5}$ dicarboxylic acids to a liquid, organic aerosol phase will not be very different as the vapor pressures of the supercooled melts are similar. In contrast, if the partitioning occurred between the gas phase and solid dicarboxylic acids, the even acids would more strongly favor the condensed phase, as their solid state vapor pressures are typically lower. These aerosol composition and phase state related differences in partitioning behavior become particularly important for acids with low water-solubility, such as succinic acid.

Another general conclusion concerns the scatter of vapor pressure data in the literature when measuring dicarboxylic acids in their solid state. Above we have shown that the vapor pressure of an effloresced glutaric or succinic acid particle decreases over time scales of days for slowly evaporating micrometer size particles. Our explanation for this behavior is that the particle only slowly transforms during evaporation to its thermodynamically stable crystalline structure or depending on the water content of the efflorescing particle, solvent inclusions increase evaporation rate. This observation supports our view that the difference between different measurements reported in the literature are at least partly due to the lack of control of the physical state of the samples under investigation. We have shown for succinic and glutaric acid, that depending on the particle history of the sample, vapor pressures deviating by more than one order of magnitude can be obtained. If from such data vapor pressures of the supercooled melt are derived, the error will be propagated. Vapor pressures of solids determined from vapor pressure data of the aqueous solution at saturation conditions seems to be more robust, see Fig. 13. This emphasizes the special importance of performing vapor pressure measurements in the aqueous state.

\section{Appendix A}

\section{Correct expressions for Eq. (5a-d) of Clegg and Seinfeld (2006)}

McGlashan (1963) discusses an empirical thermodynamic parameterization that is consistent with the Duhem-Margules relation for the excess Gibbs energy of two-component systems. Clegg and Seinfeld (2006a) used this parameterization for dicarboxylic acid-water systems and report estimated coefficients, $c_{i}$, in Table 4 of Clegg and Seinfeld (2006a). However, there is an error in the Eq. (5a and b) given in Clegg and Seinfeld (2006a), while the coefficients reported in their Table 4 were estimated with the correct expressions. The 
Table 4. Fitted parameters of Clegg and Seinfeld (2006a) for use with the empirical parameterization given in Appendix A1.

\begin{tabular}{crccccccc}
\hline acid & \multicolumn{1}{c}{$c_{i}$} & $i$ & \multicolumn{1}{c}{$c_{i}$} & $i$ & \multicolumn{1}{c}{$c_{i}$} & $i$ & $c_{i}$ & $i$ \\
\hline malonic & -0.149445 & $(1)$ & -0.403222 & $(2)$ & -0.571432 & $(3)$ & 0.628461 & $(6)$ \\
succinic & 0.291972 & $(2)$ & 0.452397 & $(8)$ & & & & \\
glutaric & -0.209091 & $(1)$ & 0.353220 & $(2)$ & 0.755191 & $(7)$ & & \\
\hline
\end{tabular}

correct expressions for water and solute activities in binary aqueous solutions of the dicarboxylic acids are (McGlashan, 1963):

$$
\begin{aligned}
\frac{g^{e}}{R T}= & x_{s}\left(1-x_{s}\right)\left[c_{1}+\sum_{i=2}^{m} c_{i}\left(1-2 x_{s}\right)^{i-1}\right] \\
\frac{d\left(\frac{g^{e}}{R T}\right)}{d x_{s}} & =\left(1-2 x_{s}\right)\left[c_{1}+\sum_{i=2}^{m} c_{i}\left(1-2 x_{s}\right)^{i-1}\right] \\
& +x_{s}\left(1-x_{s}\right)\left[-2 c_{2}-\sum_{i=3}^{m} 2(i-1) c_{i}\left(1-2 x_{s}\right)^{i-2}\right] \\
\ln \left(f_{s}\right) & =\frac{g^{e}}{R T}+\left(1-x_{s}\right) \frac{d\left(\frac{g^{e}}{R T}\right)}{d x_{s}} \\
\ln \left(f_{w}\right) & =\frac{g^{e}}{R T}-x_{s} \frac{d\left(\frac{g^{e}}{R T}\right)}{d x_{s}}
\end{aligned}
$$

where $g^{e}$ is the excess Gibbs energy of the solution per mole of total material, $x_{s}$ is the mole fraction of the acid solute (on an undissociated basis), $c_{i}(i=1,2, \ldots, m)$ are the fitted parameters shown in Table $4, f_{s}$ is the mole fraction based activity coefficient of the solute (acid) and $f_{w}$ is the activity coefficient of the solvent (water).

Acknowledgements. This work was supported by ETH Research Grant ETH-2406-3, EUROCHAMP 2, and Swiss National Science Foundation under contract No. PA00P2-126227. We would like to acknowledge fruitful discussion with Th. Peter and M. Bilde.

Edited by: M. Ammann

\section{References}

IPCC 2007: Climate Change 2007: The Physical Science Basis, in: Contribution of Working Group I to the Fourth Assessment Report of the Intergovernmental Panel on Climate Change, edited by: Solomon, S., Qin, D., Manning, M., Chen, Z., Marquis, M., Averyt, K. B., Tignor, M., and Miller, H. L., Cambridge University Press, Cambridge, UK and New York, NY, USA, 2007.

Apelblat, A. and Manzurola, E.: Solubility of oxalic, malonic, succinic, adipic, maleic, citric, and tartaric acids in water from 278.15 to 338.15 K, J. Chem. Thermodyn., 19, 317-320, 1987.
Apelblat, A. and Manzurola, E.: Solubility of ascorbic, 2furancarboxylic, glutaric, pimelic, salicylic, and o-phthalic acids in water from 279.15 to $342.15 \mathrm{~K}$, and apparent molar volumes of ascorbic, glutaric, and pimelic acids in water at $298.15 \mathrm{~K}$, J. Chem. Thermodyn., 21, 1005-1008, 1989.

Barley, M. H. and McFiggans, G.: The critical assessment of vapour pressure estimation methods for use in modelling the formation of atmospheric organic aerosol, Atmos. Chem. Phys., 10, 749767, doi:10.5194/acp-10-749-2010, 2010.

Ben-Hamo, M., Apelblat, A., and Manzurola, E.: Volumetric properties of aqueous solutions of glutaric acid, J. Chem. Thermodyn., 39, 1071-1076, 2007.

Bilde, M. and Pandis, S.: Evaporation rates and vapor pressures of individual aerosol species formed in the atmospheric oxidation of alpha- and beta-Pinene, Environ. Sci. Technol., 35, 3344-3349, 2001.

Bilde, M., Svenningsson, B., Mønster, J., and Rosenørn, T.: Evenodd alternation of evaporation rates and vapor pressures of $\mathrm{C}_{3}-$ $\mathrm{C}_{9}$ dicarboxylic acid aerosols, Environ. Sci. Technol., 37, 13711378, 2003.

Bird, R. B., Stewart, W. E., and Lightfoot, E. D.: Transport Phenomena, 2nd revised edn., John Wiley and Sons, New York, USA, 2007.

Booth, A. M., Markus, T., McFiggans, G., Percival, C. J., Mcgillen, M. R., and Topping, D. O.: Design and construction of a simple Knudsen Effusion Mass Spectrometer (KEMS) system for vapour pressure measurements of low volatility organics, Atmos. Meas. Tech., 2, 355-361, doi:10.5194/amt-2-355-2009, 2009.

Booth, A. M., Barley, M. H., Topping, D. O., McFiggans, G., Garforth, A., and Percival, C. J.: Solid state and sub-cooled liquid vapour pressures of substituted dicarboxylic acids using Knudsen Effusion Mass Spectrometry (KEMS) and Differential Scanning Calorimetry, Atmos. Chem. Phys., 10, 4879-4892, doi:10.5194/acp-10-4879-2010, 2010.

Bradley, R. S. and Cotson, S.: The vapour pressure and lattice energy of hydrogen-bonded crystals. Part II $\alpha$ - and $\beta$-anhydrous oxalic acid and tetragonal pentaerythritol, J. Chem. Soc., June, 1684-1688, 1953.

Braun, C. and Krieger, U. K.: Two-dimensional angular lightscattering in aqueous $\mathrm{NaCl}$ single aerosol particles during deliquescence and efflorescence, Opt. Express, 8, 314-321, 2001.

Camus, S., Harris, K. D. M., and Johnston, R. L.: Ab initio calculation of $2 \mathrm{H}$ quadrupole coupling constants in molecular crystals: application to polymorphs of oxalic acid dihydrate, Chem. Phys. Lett., 276, 186-195, 1997.

Cappa, C., Lovejoy, E., and Ravishankara, A.: Determination of evaporation rates and vapor pressures of very low volatility compounds: a Study of the $\mathrm{C}_{4}-\mathrm{C}_{10}$ and $\mathrm{C}_{12}$ Dicarboxylic Acids, J. Phys. Chem. A, 111, 3099-3109, 2007. 
Cappa, C., Lovejoy, E., and Ravishankara, A.: Evidence for liquidlike and nonideal behavior of a mixture of organic aerosol components, PNAS, 105, 18687-18691, 2008.

Chang, E. I. and Pankow, J. F.: Prediction of activity coefficients in liquid aerosol particles containing organic compounds, dissolved inorganic salts, and water - Part 2: Consideration of phase separation effects by an X-UNIFAC model, Atmos. Environ., 40, 6422-6436, doi:10.1016/j.atmosenv.2006.04.031, 2006.

Chang, E. I. and Pankow, J. F.: Organic particulate matter formation at varying relative humidity using surrogate secondary and primary organic compounds with activity corrections in the condensed phase obtained using a method based on the Wilson equation, Atmos. Chem. Phys., 10, 5475-5490, doi:10.5194/acp-105475-2010, 2010.

Chattopadhyay, S. and Ziemann, P.: Vapor pressures of substituted and unsubstituted monocarboxylic and dicarboxylic acids measured using an improved thermal desorption particle beam mass spectrometry method, Aerosol Sci. Tech., 39, 1085-1100, 2005.

Clegg, S. L. and Seinfeld, J. H.: Thermodynamic models of aqueous solutions containing inorganic electrolytes and dicarboxylic acids at $298.15 \mathrm{~K}-\mathrm{I}$. The acids as nondissociating components, J. Phys. Chem. A, 110, 5692-5717, 2006.

Clegg, S. L. and Seinfeld, J. H.: Thermodynamic models of aqueous solutions containing inorganic electrolytes and dicarboxylic acids at $298.15 \mathrm{~K}$ - II. Systems including dissociation equilibria, J. Phys. Chem. A, 110, 5718-5734, 2006.

Clegg, S. L., Kleeman, M. J., Griffin, R. J., and Seinfeld, J. H.: Effects of uncertainties in the thermodynamic properties of aerosol components in an air quality model - Part 1: Treatment of inorganic electrolytes and organic compounds in the condensed phase, Atmos. Chem. Phys., 8, 1057-1085, doi:10.5194/acp-81057-2008, 2008.

Colberg, C. A., Krieger, U. K., and Peter, T.: Morphological investigations of single levitated $\mathrm{H}_{2} \mathrm{SO}_{4} / \mathrm{NH}_{3} / \mathrm{H}_{2} \mathrm{O}$ aerosol particles during deliquescence/efflorescence experiments, J. Phys. Chem. A, 108, 2700-2709, 2004.

Davies, M. and Thomas, G. H.: The lattice energies, infra-red spectra, and possible cyclization of some dicarboxylic acids, T. Faraday Soc., 56, 185-192, 1960.

Decesari, S., Fuzzi, S., Facchini, M. C., Mircea, M., Emblico, L., Cavalli, F., Maenhaut, W., Chi, X., Schkolnik, G., Falkovich, A., Rudich, Y., Claeys, M., Pashynska, V., Vas, G., Kourtchev, I., Vermeylen, R., Hoffer, A., Andreae, M. O., Tagliavini, E., Moretti, F., and Artaxo, P.: Characterization of the organic composition of aerosols from Rondnia, Brazil, during the LBASMOCC 2002 experiment and its representation through model compounds, Atmos. Chem. Phys., 6, 375-402, doi:10.5194/acp6-375-2006, 2006.

de Kruif, C. G., van Ginkel, C. H. D., and Voogd, J.: Torsioneffusion vapour measurements of organic compounds, in: Quatrième Conférence Internationale de Thermodynamique Chimique/sous les auspices de l'Union Internationale de Chimie Pure et Appliquée; comité scientifique: M. Laffitte, prés., Montpellier, France, 1975.

de Villepin, J., Novak, A., and Bougeard, D.: Alpha- and betaphases of oxalic acid, $\mathrm{H}_{2} \mathrm{C}_{2} \mathrm{O}_{4}$ : vibrational spectra, normalcoordinate calculations, and intermolecular forces, Chem. Phys., 73, 291-312, 1982.

de Wit, H. G. M., Bouwstra, J. A., Blok, J. G., and de Kruif, C. G.:
Vapor pressures and lattice energies of oxalic acid, mesotartic acid, phloroglucinol, myoinositol, and thier hydrates, J. Chem. Phys., 78, 1470-1475, 1983.

Goldstein, A. H. and Galbally, I. E.: Known and unexplored organic constituents in the Earth's atmosphere, Environ. Sci. Technol., 41, 1514-1521, 2007.

Gaman, A. I., Kulmala, M., Vehkamäki, H., Napari, I., Mircea, M., Facchini, M. C., and Laaksonen, A.: Binary homogeneous nucleation in water-succinic acid and water-glutaric acid systems, J. Chem. Phys., 120, 282-291, 2004.

Hallquist, M., Wenger, J. C., Baltensperger, U., Rudich, Y., Simpson, D., Claeys, M., Dommen, J., Donahue, N. M., George, C., Goldstein, A. H., Hamilton, J. F., Herrmann, H., Hoffmann, T., Iinuma, Y., Jang, M., Jenkin, M. E., Jimenez, J. L., KiendlerScharr, A., Maenhaut, W., McFiggans, G., Mentel, Th. F., Monod, A., Prévôt, A. S. H., Seinfeld, J. H., Surratt, J. D., Szmigielski, R., and Wildt, J.: The formation, properties and impact of secondary organic aerosol: current and emerging issues, Atmos. Chem. Phys., 9, 5155-5236, doi:10.5194/acp-95155-2009, 2009.

Hansen, A. R. and Beyer, K. D.: Experimentally determined thermochemical properties of the malonic acid/water system: implications for atmospheric aerosols, J. Phys. Chem. A, 108, 34573466, 2004.

Koponen, I. K., Riipinen, I., Hienola, A., Kulmala, M., and Bilde, M.: Thermodynamic properties of malonic, succinic, and glutaric acids: evaporation rates and saturation vapor pressures, Environ. Sci. Technol., 41, 3926-3933, 2007.

Kundu, S., Kawamura, K., Andreae, T. W., Hoffer, A., and Andreae, M. O.: Molecular distributions of dicarboxylic acids, ketocarboxylic acids and $\alpha$-dicarbonyls in biomass burning aerosols: implications for photochemical production and degradation in smoke layers, Atmos. Chem. Phys., 10, 2209-2225, doi:10.5194/acp-10-2209-2010, 2010.

Legrand, M., Preunkert, S., Oliveira, T., Pio, C. A., Hammer, S., Gelencer, A., Kasper-Giebl, A., and Laj, P.: Origin of $\mathrm{C}_{2}-\mathrm{C}_{5}$ dicarboxylic acids in the European atmosphere inferred from yearround aerosol study conducted at a west-east transect, J. Geophys. Res., 112, D23S07, doi:10.1029/2006JD008019, 2007.

Marcolli, C., Luo, B. P., and Peter, T.: Mixing of the organic aerosol fractions: liquids as the thermodynamically stable phases, J. Phys. Chem. A, 108, 2216-2224, 2004.

McGlashan, M. L.: Deviations from Raoult's law, J. Chem. Educ., 40, 516-518, 1963.

Mensah, A. A., Buchholz, A., Kiendler-Scarr, A., and Mentel, T. F.: Chemical and physical properties of oxalic acid and oxalate aerosol particles, European Aerosol Conference 2009, Karlsruhe, Abstract T043A14, 2009.

Mikhailov, E., Vlasenko, S., Martin, S. T., Koop, T., and Pöschl, U.: Amorphous and crystalline aerosol particles interacting with water vapor: conceptual framework and experimental evidence for restructuring, phase transitions and kinetic limitations, Atmos. Chem. Phys., 9, 9491-9522, doi:10.5194/acp-9-9491-2009, 2009.

Ming, Y. and Russell, L. M.: Thermodynamic equilibrium of organic-electrolyte mixtures in aerosol particles, AIChE J., 48, 1331-1348, 2002.

Noyes, W. A. and Wobbe, D. E.: The vapor pressure of anhydrous oxalic acid, J. Am. Chem. Soc., 48, 1882-1887, 1926. 
Pankow, J. F.: An absorption-model of gas-particle partitioning of organic-compounds in the atmosphere, Atmos. Environ., 28, 185-188, 1994.

Peng, C., Chan, M. N., and Chan, C. K.: The hygroscopic properties of dicarboxylic and multifunctional acids: measurements and UNIFAC predictions, Environ. Sci. Technol. 35, 4495-4501, 2001.

Pope, F. D., Tong, H.-J., Dennis-Smither, B. J., Griffiths, P. T., Clegg, S. L., Reid, J. P., and Cox, R. A.: Studies of Single Aerosol Particles Containing Malonic Acid, Glutaric Acid, and Their Mixtures with Sodium Chloride. II. Liquid-State Vapor Pressures of the Acids, J. Phys. Chem. A, 114, 10156-10165, 2010.

Prenni, A. J., DeMott, P. J., Kreidenweis, S., Sherman, D. E, Russell, L. M., and Ming, Y..: The effects of low molecular weight dicarboxylic acids on cloud formation, J. Phys. Chem. A, 105, 11240-11248, 2001.

Ribeiro da Silva, M. R. D., Monte, M., and Ribeiro, J.: Vapour pressures and the enthalpies and entropies of sublimation of five dicarboxylic acids, J. Chem. Thermodyn., 31, 1093-1107, 1999.

Ribeiro da Silva, M. R. D., Monte, M., and Ribeiro, J.: Thermodynamic study on the sublimation of succinic acid and of methyland dimethylsubstituted succinic and glutaric acids, J. Chem. Thermodyn., 33, 23-31, 2001.

Riipinen, I., Svenningsson, B., Bilde, M., Gamana, A., Lehtinenc, K. E. J., and Kulmalaa, M.: A method for determining thermophysical properties of organic material in aqueous solutions: succinic acid, Atmos. Res., 82, 579-590, 2006.

Riipinen, I., Koponen, I. K., Frank, G. P., Hyvärinen, A.-P., Vanhanen, J., Lihavainen, H., Lehtinen, K. E. J., Bilde, M., and Kulmala, M.: Adipic and malonic acid aqueous solutions: surface tensions and saturation vapor pressures, J. Phys. Chem. A, 11, 12995-13002, 2007.

Roux, M. V., Temprado, M., and Chickos, J. S.: Vaporization, fusion and sublimation enthalpies of the dicarboxylic acids from $\mathrm{C}_{4}$ to $\mathrm{C}_{14}$ and $\mathrm{C}_{16}$, J. Chem. Thermodyn., 37, 941-953, 2005.

Rozaini, M. Z. H. and Brimblecombe, P.: The odd-even behaviour of dicarboxylic acids solubility in the atmospheric aerosols, Water Air Soil Poll., 198, 65-75, 2009.

Salo, K., Jonsson, Å. M., Andersson, P. U., and Hallquist, M.: Aerosol volatility and enthalpy of sublimation of carboxylic acids, J. Phys. Chem. A, 114, 4586-4594, 2010.

Tanaka, H.: The kinetic study of thermal dehydration of oxalic acid dihydrate, J. Therm. Analysis, 29, 1115-1122, 1984.

Tao, Y. and McMurry, P.: Vapor pressures and surface free energies of $\mathrm{C}_{14}-\mathrm{C}_{18}$ monocarboxylic acids and $\mathrm{C}_{5}$ and $\mathrm{C}_{6}$ dicarboxylic acids, Environ. Sci. Technol., 23, 1519, 1989.
Thalladi, V. R., Nüsse, M., and Boese, R.: The melting point alternation in $\alpha, \omega$-alkanedicarboxylic acids, J. Am. Chem. Soc., 122, 9227-9236, 2000.

Wang, H., Kawamura, K., and Yamazaki, K.: Water soluble dicarboxylic acids, ketoacids and dicarbonyls in the atmospheric aerosols over the Southern Ocean and Western Pacific Ocean, J. Atmos. Chem., 53, 43-61, 2006.

Zardini, A. A., Krieger, U. K., and Marcolli, C.: White light Mie resonance spectroscopy used to measure very low vapor pressures of substances in aqueous solution aerosol particles, Opt. Express, 14, 6951-6962, 2006.

Zardini, A. A., Sjogren, S., Marcolli, C., Krieger, U. K., Gysel, M., Weingartner, E., Baltensperger, U., and Peter, T.: A combined particle trap/HTDMA hygroscopicity study of mixed inorganic/organic aerosol particles, Atmos. Chem. Phys., 8, 55895601, doi:10.5194/acp-8-5589-2008, 2008.

Zardini, A. A. and Krieger U. K.: Evaporation kinetics of a nonspherical, levitated aerosol particle using optical resonance spectroscopy for precision sizing, Opt. Express, 17, 4659-4669, 2009.

Zardini, A. A. and Krieger U. K.: Evaporation kinetics of a nonspherical, levitated aerosol particle using optical resonance spectroscopy for precision sizing: Errata, Opt. Express, 18, 1076010761, 2010.

Zhang, Q., Jimenez, J. L., Canagaratna, M. R., Allan, J. D., Coe, H., Ulbrich, I., Alfarra, M. R., Takami, A., Middlebrook, A. M., Sun, Y. L., Dzepina, K., Dunlea, E., Docherty, K., De-Carlo, P. F., Salcedo, D., Onasch, T., Jayne, J. T., Miyoshi, T., Shimono, A., Hatakeyama, S., Takegawa, N., Kondo, Y., Schneider, J., Drewnick, F., Borrmann, S., Weimer, S., Demerjian, K., Williams, P., Bower, K., Bahreini, R., Cottrell, L., Griffin, R. J., Rautiainen, J., Sun, J. Y., Zhang, Y. M., and Worsnop, D. R.: Ubiquity and dominance of oxygenated species in organic aerosols in anthropogenically-influenced Northern Hemisphere midlatitudes, Geophys. Res. Lett., 34, L13801, doi:10.1029/2007GL029979, 2007.

Zuend, A., Marcolli, C., Luo, B. P., and Peter, T.: A thermodynamic model of mixed organic-inorganic aerosols to predict activity coefficients, Atmos. Chem. Phys., 8, 4559-4593, doi:10.5194/acp8-4559-2008, 2008.

Zuend, A., Marcolli, C., Peter, T., and Seinfeld, J. H.: Computation of liquid-liquid equilibria and phase stabilities: implications for RH-dependent gas/particle partitioning of organic-inorganic aerosols, Atmos. Chem. Phys., 10, 7795-7820, doi:10.5194/acp10-7795-2010, 2010. 